\title{
Focus and the Interpretation of Pitch Accent: Disambiguating Embedded Questions*
}

\author{
AMY SCHAFER, ${ }^{a}$ KATY CARLSON, \\ CHARLES CLIFTON, JR., and LYN FRAZIER \\ ${ }^{a} U C L A$ \\ ${ }^{b}$ University of Massachusetts, Amherst
}

KEY WORDS

focus

pitch accents

prosody

sentence

interpretation

syntactic ambiguity

\section{ABSTRACT}

It has been suggested that prosodic disambiguation of sentences is largely a matter of prosodic phrasing. Ambiguities can be resolved if a prosodic break aligns with a major syntactic boundary of one structure but not another. The placement of pitch accents is viewed as playing only a supporting role (cf. Price, Ostendorf, Shattuck-Huffnagel, \& Fong, 1991). This view of prosodic disambiguation does not apply to all structures of a language. We report five experiments studying ambiguous sentences like (i) and (ii):

(i) I asked the pretty little girl WHO is cold.

I asked the pretty little girl who is COLD.

(ii) Joshua began to wonder WHEN his girlfriend got a tattoo.

Joshua began to wonder when his girlfriend got a TATTOO.

The presence of a prominent pitch accent on the interrogative constituent (who, when) biased listeners to an embedded question interpretation whereas its absence biased them to a relative clause (i) or temporal adjunct (ii) analysis. The results suggest that accent, like prosodic breaks, can play a central role in guiding sentence comprehension.

\section{INTRODUCTION}

It is generally assumed that a questioned constituent - the wh-word in (1) and (2) — is, by default, focused. In English, a high pitch accent (Pierrehumbert, 1980; Pierrehumbert \& Hirschberg, 1990; Selkirk, 1984) is commonly used to convey focus. A natural way of asking a question, presupposing little or nothing from context, is illustrated in (1a) (where uppercase

* Acknowledgements: Schafer is now at the Department of Linguistics, UCLA. Frazier and Carlson are in the Department of Linguistics, and Clifton in the Department of Psychology, University of Massachusetts. This research was supported by research grant HD-18708 and training grant HD-07327 to the University of Massachusetts. We would like to thank Maureen Hutchins, Danielle Michaud, and Janina Radó for assisting in the experiments. Schafer's address: Department of Linguistics, 3125 Campbell Hall, UCLA, Los Angeles, CA 90095-1543; e-mail: <schafer@ucla.edu>

Address for correspondence: Charles Clifton, Department of Psychology, University of Massachusetts,Amherst, MA 01003; e-mail: <cec@cpsych.umass.edu> 
letters are used to indicate a prosodic prominence, e.g., a high pitch accent). Given a context that makes one or more of the phrases in the question "old" or "contrastive," it is possible to place a high pitch accent on only a subset of the words in the question, as illustrated in $(1 \mathrm{~b}-\mathrm{d})$. For present purposes, however, the important point is that who can receive explicit focus in a direct question.

(1) a. WHO did JOHN SEE?

b. wHO did John see?

c. Who did JoHN see?

d. Who did John SEE?

This focus property of direct questions like (1) holds true of the indirect question interpretations of (2), as well.

(2) a. I asked the teacher WHO LEFT.

b. I asked the teacher wHO left.

c. I asked the teacher who LEFT.

The sentences in (2) are ambiguous between an embedded question interpretation ("I asked the teacher something, namely, I asked her who left") and a relative clause interpretation ("It was the teacher who left that I asked about something"). The questioned constituent who can be explicitly focused, but (in our judgment) the relative pronoun who cannot receive focus (apart from unusual contrastive uses of relative clauses). Thus, the presence of a high pitch accent on who in (2a) or (2b) should discourage the relative clause interpretation and encourage the embedded question interpretation. The absence of a high pitch accent on who in (2c) should have the converse effect, encouraging a relative clause analysis.

In the present paper we report four experiments designed to investigate whether pitch accents are used by listeners to disambiguate otherwise ambiguous syntactic strings, plus one experiment using written materials. Experiments 1 through 4 contrast embedded question and relative clause analyses. Experiment 5 contrasts an embedded question and a temporal adjunct analysis.

We think the role of pitch accent in disambiguating questions is of interest for several reasons. The syntactic processing literature abounds with examples where the presence of a prosodic break biases or fully disambiguates ambiguous structures (Kjelgaard \& Speer, 1999; Lehiste, 1973; Price et al., 1991; Speer, Kjelgaard, \& Dobroth, 1996; cf. Cutler, Dahan, \& Van Donselaar, 1997). However, few studies have examined the role of pitch accents or focus placement in syntactic disambiguation, and even fewer show an effect. Price et al. (1991) even concluded that break phenomena often disambiguate ambiguous syntactic structures, but pitch accents play only a minor supporting role. Speer, Crowder, and Thomas (1993) investigated the role of accent in disambiguating "FRYing chickens" versus "frying СНІСКens" and did find an effect. Schafer, Carter, Clifton, and Frazier (1996) found a robust effect of pitch accents in the attachment of relative clauses in ambiguous structures such as (3). Listeners were more likely to take the relative clause to modify the more deeply embedded NP (the plane) when its head received an $\mathrm{H}^{*}$ accent, as in (3a), than when it did not but the head of the higher NP did, as in (3b). The effect was increased 
further when the head received a contrastive $\left(\mathrm{L}+\mathrm{H}^{*}\right)$ accent.

(3) a..... the propeller of the PLANE that the mechanic was carefully examining.

b..... the PROPELLER of the plane that the mechanic was carefully examining.

Unlike Speer et al. (1993), Schafer et al. (1996) explicitly controlled for concomitant break phenomena, ensuring that their results were not due to speakers' tendency to place a break before accented constituents (although Speer (personal communication) indicated that break phenomena were not responsible for the effects found in Speer et al.).

Carlson (submitted) examined ambiguous ellipsis constructions like Bob insulted the guests during dinner and Sam during the dance, which are ambiguous between a gapping analysis (in which Sam insulted the guests) and a VP conjunction analysis (in which Bob insulted Sam). She found that placing prominent pitch accents on BOB and DINNER, and on SAM and DANCE, increased the frequency with which listeners reported the normallyunpreferred gapping analysis, while placing the pitch accent on GUESTS rather than оn вов favored the VP conjunction analysis. Carlson suggested that listeners interpreted the pitch accents as marking contrastive focus and preferred to analyze the coordinate phrases in a way that would allow the contrasting phrases to occupy syntactically parallel positions. Finally, Warren, Grabe, and Nolan (1995) found that the presence of stress-shift on Hong Kong in phrases like Hong Kong problems slowed naming times to continuations requiring a major syntactic boundary to be postulated after the stress-shifted item (e.g., "Whenever parliament discussed HONG Kong problems arise..."), but only for a subset of items which could not typically be analyzed as carrying contrastive focus on the stressed syllable. To our knowledge, these are currently the only studies that have examined the role of focus, as conveyed by pitch accent, on the disambiguation of ambiguous syntactic structures.

Before making explicit experimental predictions, we briefly sketch our background assumptions. We do not propose our experiments as a test of these assumptions; rather, we wish to make one defensible set of assumptions explicit, for the sake of clarity. We assume Selkirk's $(1984,1995)$ basic theory of focus. Each pitch accent introduces f-marking into the syntactic representation of the word bearing the accent. In the syntax, f-marking may project to a constituent XP if its head X is f-marked. F-marking may also project from an internal argument of $\mathrm{X}$ to the head, $\mathrm{X}$. In the semantic component, a constituent which is not $\mathrm{f}$-marked is interpreted as given. A constituent which is f-marked may be interpreted as contrastive, or as noncontrastive and new.

We assume the intonational theory of Pierrehumbert and Beckman (1988; Beckman $\&$ Pierrehumbert, 1986) where each utterance is claimed to contain at least one full intonational phrase (IPh). An IPh consists of one or more intermediate intonational phrases (iph), each containing one or more pitch accents (e.g., $\mathrm{H}^{*}, \mathrm{~L}^{*}$ ). Each iph must end with a phrase accent (L-, H-) and each IPh with a phrase accent and a boundary tone (L\%, H\%). We also assume the theory of break indices incorporated in the ToBI transcription system (Beckman \& Hirschberg, 1994; Silverman, Beckman, Pitrelli et al., 1992) in which an iph boundary is typically associated with a level 3 break and an IPh boundary with a level 4 break.

In order to describe our experimental materials adequately, we must go beyond the boundaries of these theories and acknowledge that, if an iph contains multiple pitch accents, these accents can differ in perceptual prominence and the final (nuclear) pitch accent is 
not necessarily the most prominent accent in the phrase. For instance, some of our materials have an $\mathrm{H}^{*}$ accent on the initial who but also have downstepped ! $\mathrm{H}^{*}$ accents or $\mathrm{L}^{*}$ accents on some following words in the intermediate phrase. We submit that, as produced in our experimental materials, the word with the initial $\mathrm{H}^{*}$ accent is the most prominent and thus has the most salient focus. We do not address here the question of how best to represent this notion of prominence or salience of focus within the theories we assume, but acknowledge that it might require some extension or modification of the theories (cf. Ladd, 1996, especially Chapter 6, for discussion of some possibilities).

We cast our experimental proposal about how pitch accent and focus might disambiguate some sentences in terms of the hypothesis in (4):

(4) a. A (prominent) pitch accent generally introduces focus (f-marking in the syntactic representation of the constituent).

b. An interrogative constituent, by default, should be focused.

\section{Prediction:}

Therefore, even though an interrogative constituent does not have to be accented, the presence of accent on a $w h$-constituent biases listeners to an interrogative analysis of the $w h$-constituent. The absence of a (typically high) pitch accent on a wh-constituent biases listeners toward a noninterrogative analysis of the $w h$-constituent.

Pitch accent is not the only factor that can affect listeners' interpretations of sentences like (2) that are ambiguous between question and other (e.g., relative clause) interpretations. For instance, Jun and Oh (1996) have shown that a sentence in Korean that is ambiguous between a wh-question and a yes-no question can be disambiguated by producing the word that is ambiguous between a wh-pronoun and an indefinite pronoun (e.g., /nuka/, who or anyone) in its own accentual phrase for a yes-no question, but using an accentual phrase that spans the ambiguous word and the following verb in a wh-question. ${ }^{1}$ Jun and Oh note that this difference has been described as a difference in prosodic prominence (so that a more prominent instance of the ambiguous word is more likely to be taken as a whword). In their own discussion, however, they emphasize the immediate role that accentual phrasing seems to play in disambiguating the forms.

It is possible that prosodic phrasing can play a role in disambiguating English interrogative and relative pronouns. For instance, the presence of an IPh boundary before the wh-word might encourage one interpretation or the other. In Experiments 1 and 2, we attempt to eliminate any such boundaries. Experiment 3 explicitly investigates the possible effect of an IPh boundary.

The length of the constituents involved may interact with the effects of pitch accent or the presence of a break if a listener is sensitive to the default effects of length on the prosody of an utterance and takes these effects into account in interpreting prosody. Different specific aspects of prosody could be involved in this effect. For instance, Gee and Grosjean

1 An accentual phrase in Korean is similar to a phonological or intermediate phrase in English in that it is the level of prosodic phrasing below the (full) intonationalphrase. The prosodic structure of English and Korean differ in several importantfeatures, however; see Jun (1993) for a discussion of the Korean system. 
(1983) noted that speakers tend to insert breaks that have the effect of keeping prosodic phrases relatively equal in length. Lengthening the complement of a wh-phrase (e.g., changing (2) into I asked the teacher who quickly and silently left) might encourage inserting a high-level prosodic break before who because doing so would avoid a very long single intonational phrase and result in two IPh's of nearly-equal length, unlike the case where the $w h$-phrase is short. If this is so, then any effect of the absence of an IPh boundary before a $w h$-word could be magnif ied in long examples as compared to short ones. Similarly, the presence of an $\mathrm{H}^{*}$ pitch accent on a $w h$-word may be encouraged by the fact that speakers tend to favor alternating patterns of prosodically prominent and nonprominent material, avoiding long stretches of unaccented material (cf. discussions of the Rhythm Rule; Liberman \& Prince, 1977; Nespor \& Vogel, 1989). Thus, the absence of an $\mathrm{H}^{*}$ accent on a $w h$-word that begins a relatively long stretch of unaccented or weakly accented material might serve as evidence that focus on the word would be inappropriate.

The experiments to be reported here thus examine the effect of prominent pitch accents, prosodic boundaries, and length of ambiguous clauses on the interpretation of whconstituents. Their main goal is to determine whether perceptual prominence of an accent can play a role in disambiguation. In these experiments, we attempt to control (or to explicitly manipulate) prosodic boundaries. We accept that the presence of prosodic boundaries can syntactically disambiguate various forms of some sentences, but here we attempt to establish the existence of prosodic disambiguation that is not dependent upon the existence of salient prosodic boundaries. As indicated earlier, we do not take our results to carry strong implications about the proper representation of focus and other prosodic phenomena. We acknowledge the existence of theories of focus other than the one we adopt, theories that trace differences in prosodic prominence to underlying differences in prosodic structure (cf. Ladd, 1996), and we acknowledge that psycholinguistic applications of these theories might well be able to account for the results we will report.

Experiment 1 reports an experiment in which listeners heard sentences containing $w h$-phrases that are ambiguous between embedded question and relative clause interpretations. We propose that listeners will be sensitive to the presence of a prominent $\mathrm{H}^{*}$ pitch accent on the $w h$-constituent. The presence of such a pitch accent on the $w h$-constituent will discourage taking the relative clause interpretation, but support the embedded question interpretation. The experiment also manipulated the length of the clause to determine whether the preferred interpretation of the sentence would be affected by phrase length.

\section{EXPERIMENT 1}

\section{Method}

Materials. To test the effects of pitch accent and constituent length, we constructed 16 sentences like those in (5), which are ambiguous between an embedded question analysis and a relative clause analysis.

(5) a. I asked the pretty little girl wHO's cold.

b. I asked the pretty little girl who's COLD.

c. I asked the pretty little girl wHO is very cold.

d. I asked the pretty little girl who is very COLD. 
There were four versions of each sentence, as in (5). These experimental sentences, together with 48 filler sentences and 10 practice sentences, were recorded by a phonetically-trained female graduate student of linguistics. She avoided placing a full intonational phrase boundary before the embedded clause and avoided a rise at the end of the sentence. Two sentence types (illustrated in $(5 \mathrm{a}, \mathrm{b})$ ) contained a short ambiguous string: who's cold. Two $(5 \mathrm{c}, \mathrm{d})$ contained a longer ambiguous string: who is very cold. The short strings averaged 2.25 syllables in length, and the long ones averaged 5.63 syllables. Two forms $(5 \mathrm{a}, \mathrm{c})$ contained a prominent $\mathrm{H}^{*}$ pitch accent on the wh-constituent ( who, who's) but no prominent pitch accent elsewhere in the ambiguous string (i.e., only low pitch accents, downstepped pitch accents, or no pitch accents). Two $(5 \mathrm{~b}, \mathrm{~d})$ contained a prominent $\mathrm{H}^{*}$ pitch accent on the final word of the sentence but nowhere else in the ambiguous string including on the $w h$-constituent. The words we identify as being prominently accented were produced with both $\mathrm{H}^{*}$ pitch accents and salient indications of stress. For example, prominently accented words had longer durations than nonprominently accented words (see the following acoustic analyses). The content words in each sentence generally received $\mathrm{L}^{*}$ pitch accents, notably less prominent than the $\mathrm{H}^{*}$ accented words but still accented. Intermediate phrase breaks (iph boundaries) appeared between the wh-word and the word that preceded it, and an additional iph boundary appeared after most of the matrix clause subjects. All experimental sentences and their tonal transcriptions in the ToBI system (Beckman \& Hirschberg, 1994; Silverman et al., 1992) appear in Appendix A.

We expected more embedded question interpretations to be assigned in $(5 \mathrm{a}, \mathrm{c})$, where who receives an $\mathrm{H}^{*}$ accent, than in $(5 \mathrm{~b}, \mathrm{~d})$ where it does not. We had no clear prediction of the effect of length of the ambiguous clause. However, we thought that clause length might interact with certain prosodic configurations. It might seem reasonable to assume that the presence of an IPh boundary before the wh-constituent would bias against a restrictive relative clause, and conversely, that its absence might favor one. However, we have also suggested that an IPh boundary might become more likely as the length of the ambiguous clause increases. If this is so, then the absence of the IPh boundary before a long ambiguous phrase might constitute especially strong evidence against an embedded question interpretation, favoring relative clause interpretations of long clauses. Therefore, for these materials, which had no medial IPh boundaries, we expected to find more relative clause interpretations in the long than the short conditions.

To check that comparable boundaries were present before the accented word (who) in all conditions, we measured the duration and F0 maximum of the word preceding who (e.g, girl). We measured F0 maxima in this context to obtain evidence about the existence of low phrase accents. Our goal was to assess the possibility that the forms with an accented who (a and $\mathrm{c}$ versions) and the forms with an accented final word ( $\mathrm{b}$ and $\mathrm{d}$ versions) differed in the frequency of phrasal boundaries before who. F0 maxima should be higher in the absence of a low phrase accent than if such an accent is present. In the (a) and (c) versions, a production without a low phrase accent should show monotonic interpolation between the pitch of the high pitch accent on who and the preceding low pitch accent, and thus show higher F0 maxima in the absence of a low phrase accent. In the (b) and (d) versions, a production without a low phrase accent often shows a slight rise between low pitch accents, and thus should show higher F0 maxima in the absence of a low phrase accent. Higher F0 maxima in the $(b, d)$ conditions than in the $(a, c)$ conditions would suggest a greater tendency 


\section{TABLE 1}

Acoustic analysis of the Experiment 1 materials

\begin{tabular}{ccc}
\multicolumn{3}{c}{ Region (illustrative words) } \\
\hline girl & who & cold \\
\hline
\end{tabular}

Condition

A (short clause, wHO)

B (short clause, COLD)

C (long clause, wHO)

D (long clause, COLD)

$\operatorname{Duration}(\mathrm{ms})$

$\begin{array}{lll}529 & 495 & 565 \\ 508 & 352 & 685 \\ 514 & 535 & 521 \\ 518 & 365 & 651\end{array}$

FO maximum $(\mathrm{Hz})$

\begin{tabular}{llll}
\hline A & 176 & 259 & 186 \\
$\mathrm{~B}$ & 165 & 183 & 233 \\
$\mathrm{C}$ & 174 & 261 & 171 \\
$\mathrm{D}$ & 167 & 188 & 231 \\
\hline
\end{tabular}

Note: values are means over all sentences

to have low phrase accents in the embedded-question-biased sentences $(a, c)$ than in the relative-clause-biased sentences $(b, d)$.

The values of duration and F0 maximum of the word preceding who are presented in Table 1 . We conducted $2 \times 2$ (position of prominent accent $\times$ length) analyses of variance on these acoustic measures (using items as the random factor). The word preceding who was slightly longer when who was accented than when cold was (529 vs. $508 \mathrm{~ms}$ ), though the effect was not significant, $F(1,15)=1.15, p>.25$. All other duration contrasts involving this word were thoroughly nonsignificant. The F0 maximum values on the word before who were higher preceding a prominently accented word than a word without prominent accent $\left(175\right.$ vs. $\left.166 \mathrm{~Hz} ; F(1,14)=31.06, p<.001^{2}\right)$, possibly reflecting a phonetic effect of the upcoming high- or low-pitched material on the realization of the preceding tones (and providing evidence against the greater prevalence of low phrase accents in the accentedwho than the accented-cold condition). As shown in the tonal transcriptions in the Appendix, all sentences were produced with intermediate phrase boundaries before who, and the conditions were comparable in terms of the frequency of high versus low phrase accents occurring at the end of the intermediate phrase.

Comparable measurements were made for the accented wh-constituent (who's or who plus the following copula or auxiliary) and are presented in the next column of Table 1. The duration of this constituent was longer when who received an $\mathrm{H}^{*}$ accent than when it did not (517 vs. $359 \mathrm{~ms} ; F(1,15)=295.32, p<.001)$. In addition, the accented who was longer when it preceded a long embedded clause (condition c) than when it preceded a short embedded clause (condition a) (535 vs. $499 \mathrm{~ms}, F(1,15)=4.95, p<.05$ ), but this is probably

Degrees of freedom are 14 because it was impossible to obtain adequate pitch measurements on one sentence 
just a matter of the fact that a full copula or auxiliary is longer than a contracted one. The F0 analysis again showed that higher F0 maxima occurred on the who with an $\mathrm{H}^{*}$ accent than the who with a less prominent accent $(260$ vs. $185 \mathrm{~Hz} ; F(1,14)=1452.3, p<.001)$. The two accented conditions (a,c) did not differ from each other.

When the final adjective received a prominent $\mathrm{H}^{*}$ accent, duration of the adjective was longer than when it did not have a prominent accent $(668 \mathrm{vs} .543 \mathrm{~ms} ; F(1,15)=111.46$, $p<.001)$. The adjectives in the two short conditions $(a, b)$ were also longer than in the long conditions, $F(1,15)=7.31, p<.02$. This difference was significant when the adjectives were prominently accented ( $689 \mathrm{vs} .651 \mathrm{~ms} ; t(15)=2.47, p<.02)$ but only questionably so when they were not (565 vs. $521 ; t(15)=1.92, p<.08)$. The F0 maxima were higher for $\mathrm{H}^{*}$ accented adjectives than for adjectives without an $\mathrm{H}^{*}(232 \mathrm{vs.} 179 \mathrm{~Hz} ; F(1,14)=227.50$, $p<.001)$ and for short than for long clauses, $F(1,14)=35.39, p<.001$. However, this latter effect was qualified by the interaction between clause length and accent position, being significant $F(1,14)=25.01, p<.001$. When who was accented (a vs. c), the short condition exhibited a higher F0 maximum than the long condition $(186$ vs. $171 \mathrm{~Hz} ; t(14)=8.69$, $p<.01$ ), as would be expected from the adjective's adjacency to the $\mathrm{H}^{*}$-accented who given the rules for tone interpolation. However, the difference was nonsignificant when the adjective was prominently accented $(233$ vs. $231 \mathrm{~Hz})$.

To summarize, prominently accented constituents were significantly longer than the corresponding constituents without a prominent accent and they exhibited higher F0 maxima, verifying the basic accent manipulation in the experimental materials. No strong prosodic break preceded the CP (e.g., who is cold). Differences between the short and long conditions were primarily isolated to the sentence-final adjective, which showed longer durations in the short conditions.

Subjects and procedures. Thirty-four students at the University of Massachusetts participated in individual half-hour sessions for course credit. After hearing the 10 practice sentences, they heard the 64 sentences in the experiment presented by a computer in an individually-randomized order. They were instructed to pull a trigger as soon as they had understood the sentence. After they responded, a question appeared on a video screen. For the experimental sentences, the question was simply What happened? and the subject was supposed to provide a paraphrase of the sentence. The experimenter told the subject to use different words in a different order from the sentence he or she heard, and insisted on a syntactic (not just a prosodic) disambiguation. The experimenter then scored the response as an embedded question, a relative clause, or (when the subject could not disambiguate), "other."

\section{Results and Discussion}

The data appear in Table 2 in terms of percentages of embedded question, relative clause, and "other" paraphrases. The percentage embedded question values were subjected to one-way analyses of variance, comparing all four conditions. The differences among the conditions were highly significant, $F 1(3,99)=10.79 ; F 2(3,45)=10.85 ; p<.001$. The standard error of a difference between two means was $4.3 \%$ both by subjects and items; thus, a difference of greater than 8.6 percentage points can be considered significant by a simple $t$-test. 


\section{TABLE 2}

Percentage choices of Embedded Question, Relative Clause, and "Other" Interpretations, Experiment 1 (and Time to accept sentence, measured from end of sentence)

\begin{tabular}{llllc}
\hline & \multicolumn{3}{c}{ Response } \\
\cline { 2 - 4 } Condition & $\begin{array}{l}\text { Embedded } \\
\text { Question }\end{array}$ & $\begin{array}{l}\text { Relative } \\
\text { Clause }\end{array}$ & Other & Acceptance \\
& 39.0 & 47.1 & 14.0 & Time (ms) \\
\hline A (short clause, WHO) & 26.5 & 61.8 & 11.8 & 1277 \\
B (short clause, COLD) & 24.3 & 58.5 & 16.7 & 1276 \\
C (long clause, WHO) & 14.8 & 62.5 & 22.8 & 1194 \\
D (long clause, COLD) & & & & 1256 \\
\hline
\end{tabular}

Examination of the means thus indicates that placing a prominent pitch accent on who led to substantially more embedded question responses than placing a prominent pitch accent on cold, 32 versus $21 \%$, supporting the hypothesis stated in (4). Embedded question responses were less frequent in the long than the short sentences, 33 versus $20 \%$, a difference that was closely comparable for both accented and unaccented who sentences.

Comparable analyses were carried out on the percentage relative clause values. The differences among all four conditions were marginally significant, $F 1(3,99)=2.76, p<.05$; $F 2(3,45)=2.66, p<.06$, with standard errors of differences of $4.1 \%$ and $4.2 \%$ for subjects and items, respectively. The primary hypothesis was again supported: Placing a pitch accent on who decreased the percentage of relative clause responses. However, the percentages of relative clause responses indicated that lengthening the embedded constituent increased the frequency of relative clause interpretations when who was prominently accented but not when the final word was accented (so that the effect of a pitch accent was significant in short, but not in long, embedded clauses). This might mean that listeners do not take the presence of a prominent pitch accent on who as clear evidence for the presence of focus when it appears in a long clause. The interpretation of this effect is unfortunately unclear, because lengthening the embedded clause increased the percentage of "other" responses, not the percentage of embedded question responses, when the final word (cold) in the clause was prominently accented. This could possibly reflect a memory problem with the longer sentences in general, or perhaps specifically with sentences like (5d) that have a long stretch of rhythmically and prosodically undifferentiated material before the final prominent pitch accent. It may also reflect greater difficulty in paraphrasing sentences with long relative clauses.

The times (measured from the end of each sentence) to indicate comprehending a sentence did not differ significantly among conditions (see Table 2, "Acceptance Time").

\section{EXPERIMENT 2}

Experiment 1 provided clear support for the hypothesis in (4), linking pitch accent, focus, and question versus relative clause interpretation. Unfortunately, it provided somewhat unclear evidence about the effect of length on the interpretation of a pitch accent. The 


\section{TABLE 3}

Acoustic analysis of the Experiment 2 materials

\begin{tabular}{lccc}
\hline & \multicolumn{3}{c}{ Region (illustrative words) } \\
\cline { 2 - 4 } & girl & who & cold \\
\cline { 2 - 4 } Condition & \multicolumn{3}{c}{ Duration (ms) } \\
\hline A (short clause, wHO) & 474 & 227 & 459 \\
B (short clause, COLD) & 450 & 182 & 510 \\
C (long clause, WHO) & 467 & 233 & 429 \\
D (long clause, COLD) & 472 & 179 & 489 \\
& & Fo maximum $(H z)$ & \\
\hline A & 194 & 240 & 190 \\
B & 195 & 195 & 229 \\
C & 195 & 236 & 225 \\
D & 195 & 193 & 225 \\
\hline Note:
\end{tabular}

Note: values are means over all sentences

frequency of embedded question paraphrases indicated that the presence of an $\mathrm{H}^{*}$ pitch accent on the $w h$-word and the length of the $w h$-constituent had independent effects on judgment. However, the percentages of relative clause paraphrases suggested that the effect of pitch accent was less for long than for short constituents. There was a substantial increase in the unscorable "other" responses for the long sentences, suggesting a memory problem or some uncertainty about the analysis of the sentence. Experiment 2 was conducted to resolve this interpretive uncertainty by changing the paraphrase requirement to a two-choice requirement. Subjects were given two choices of what a sentence might mean, and required to indicate which matched their understanding.

In addition, the sentences were re-recorded in Experiment 2, by another phonetically trained linguist, to provide some generality of the Experiment 1 results. The sentences in Experiment 1 were said rather slowly and deliberately, with very strong pitch accents on the accented words. The sentences for Experiment 2 were produced with largely the same phonological specifications, but were spoken more quickly and with subjectively less extreme pitch accents. As in Experiment 1, the speaker placed an iph boundary before the wh-word, but unlike Experiment 1, the speaker nearly always used a low phrase accent.

\section{Method}

Materials. The sixteen experimental sentences (illustrated in 5) were recorded (in four forms each) together with 38 filler sentences and seven practice sentences. They were acoustically analyzed in the same way as in Experiment 1 . The sentences and their ToBI transcriptions appear in Appendix B, and the results of the acoustic analyses appear in Table 3.

Analyses of variance like those conducted in Experiment 1 were carried out on the Experiment 2 acoustic measures. The pre-accented word ( irl $)$ was shorter in the short/last word accented condition $(450 \mathrm{~ms}$ ) than in the other three conditions (467 to $473 \mathrm{~ms}$ 
interaction, $F(1,15)=8.41, p<.02$ ). It did not differ in pitch among the conditions (194 to $195 \mathrm{~Hz}$ ). The ToBI analysis verified that all sentences except one were produced with an iph boundary marked by a low phrase accent at the clause boundary. The exception (in the short, accented who condition) contained an intonational phrase boundary with a low phrase accent and low boundary tone.

In the Experiment 2 materials, an attempt was made to measure the duration of who prior to the onset of the copula or auxiliary in the long clause condition. While determining the transition between the vowels of who and the copula is difficult, the pronunciation of the materials used in Experiment 2 permitted us to do so with some confidence. This duration was longer when who was prominently accented than when it was not (231 vs. $181 \mathrm{~ms} ; F(1,15)=125.49)$. Unlike Experiment 1 , who did not differ in length when it preceded a long embedded clause (condition c) versus when it preceded a short embedded clause (condition a), 233 versus $228 \mathrm{~ms}$. The F0 maximum analysis again showed that higher F0 maxima occurred on the prominently accented who than on the who without prominent accent $(238$ vs. $194 \mathrm{~Hz} ; F(1,15)=683.63)$ but the accented conditions (a,c) did not differ from each other $(p>.15)$. Note that the durations are much shorter than in Experiment 1 and the F0 maxima lower, reflecting the faster speech rate and the less extreme pitch accents.

When the final adjective was prominently accented, its duration was longer than when it was not (500 vs. $444 \mathrm{~ms} ; F(1,15)=125.27$ ). As in Experiment 1, the adjectives in the two short conditions (a,b) were longer than in the long conditions (c,d), $F 1(15)=7.18, p<.02$. The F0 maximum was higher for accented than unaccented adjectives $(227 \mathrm{vs.} 187 \mathrm{~Hz}$; $F(1,15)=644.10)$. The short conditions exhibited higher F0 maxima than the long conditions, both when who was accented (a vs. c; 190 vs. $184 \mathrm{~Hz}, t(15)=2.97, p<.01$ ) and when it was not (b vs. d; 229 vs. $225 \mathrm{~Hz}, t(15)=2.78, p<.02$ ). As in Experiment 1, prominently accented constituents were longer than ones without prominent accent and had higher F0 maxima.

Subjects and Procedure. Fifty-four University of Massachusetts students were tested in individual half-hour sessions. The procedure was just like that of Experiment 1, except that, instead of being asked to paraphrase the heard sentences (by answering the question "What happened"), subjects were given two choices of what the sentence meant and were required to choose one. For instance, they might see What happened? together with the two alternative answers I asked the girl which person was cold and I asked the cold girl something, and they had to pull a trigger under the answer they considered correct. The time taken to pull the trigger was measured from the onset of the question and the alternative answers. However, because the experimental conditions differed substantially in the frequency of the two responses, which were not counterbalanced for responding hand, comparisons of response time between conditions are uninterpretable and therefore the response times are not presented.

\section{Results}

Table 4 presents the percentages of relative clause interpretations. Percentages of embedded question interpretations are not presented; they are the complement of relative clause percentages, because subjects were forced to make one of two responses. Accenting who led to significantly fewer relative clause choices, 46 versus $66 \%, F 1(1,53)=34.52$; 


\section{TABLE 4}

Percentage Choices of Relative Clause Interpretations, Experiment 2 (and Time to Accept the Sentence)

\begin{tabular}{lcc}
\hline Condition & $\begin{array}{c}\text { Percentage } \\
\text { Relative Clause }\end{array}$ & $\begin{array}{c}\text { Acceptance } \\
\text { Time }(\mathrm{ms})\end{array}$ \\
\hline A (short clause, WHO) & 34.1 & 1132 \\
B (short clause, COLD) & 57.4 & 1165 \\
C (long clause, WHO) & 57.9 & 1035 \\
D (long clause, COLD) & 75.3 & 1178 \\
\hline
\end{tabular}

$F 2(1,15)=44.94, p<.001$. A longer embedded clause was associated with more relative clause interpretations than a shorter embedded clause, 67 versus $46 \%, F 1(1,53)=35.88$; $F 2(1,15)=39.21, p<.001$. The interaction was nonsignificant $(F s<1.12)$. The results are consistent with the percentage embedded question choices in Experiment 1, suggesting that some other factor was inhibiting relative clauses as paraphrases in that experiment.

As in Experiment 1, the reaction times measured from sentence end, to indicate comprehension of the sentences, did not differ among conditions ( $p>.10$; see Table 4$)$.

\section{Discussion}

The interpretation data indicate that listeners take a prominent pitch accent on a $w h$-word as an indicator of focus, which is in turn taken to indicate a question interpretation. The data also indicate that listeners take constituent length into account: Long ambiguous clauses are more likely to be taken as relative clauses than short ones are. Perhaps our listeners take the absence of an IPh break before a long phrase as evidence especially favoring a relative clause. If that were the case, then introducing an IPh break before the who would reduce the frequency of relative clause interpretations, especially before a long ambiguous clause. Experiment 3 was designed to explore this possibility.

\section{EXPERIMENT 3}

Experiment 3 contrasted new pronunciations of the sentences used in Experiments 1 and 2. All items were pronounced with prominent accent on the final adjective (cold in the example). Each sentence had a long and a short version, each with an IPh or only an iph boundary before the who. The experiment tested two conjectures. First, it was designed to evaluate our proposal, based on intuition, that an IPh before the who would discourage relative clause (at least restrictive relative clause) interpretations. Second, it evaluated the suggestion made at the end of Experiment 2 for why relative clause interpretations were especially frequent for long ambiguous clauses; this suggestion predicted that the preference for relative clause interpretations would become smaller if an IPh introduced the ambiguous phrase.

Experiment 3 also serves to address some potential concerns about the proper interpretation of Experiments 1 and 2. We have presented these experiments as showing that the presence of a perceptually prominent pitch accent, signaling focus, served to disambiguate 
our sentences. We acknowledge that other prosodic factors could matter as well. We have suggested that the presence of a boundary immediately before the wh-word might have implications for interpreting the ambiguous clause. Extrapolation of the Jun and Oh (1996) finding that a Korean accentual phrase boundary after the word that corresponds to our $w h$-word encourages listeners to interpret a Korean sentence as a yes-no question rather than a wh-question could suggest that a prosodic boundary after the $w h$-word might matter in English. We strongly suspect that the Korean tendency to eliminate accentual phrase boundaries after a focused $w h$-word is part of the phonology of that language (Jun, 1993) and not an effect that can be directly translated to the ambiguity we tested in English. Further, we are quite convinced that no prosodic boundary higher than a word-level boundary intervened between who in our materials and the sentence-final adjective. Therefore, we very much doubt that a perceived prosodic boundary after the $w h$-word could be responsible for our observed effects of pitch accent.

We have also argued that our materials equated our pitch accent conditions in the presence of prosodic boundaries that could disambiguate our sentences. While our ToBI transcription and the acoustic measures we have presented support this argument, we acknowledge that the ToBI transcription has an element of subjectivity, and that we have not presented all possible acoustic measures. By determining whether there is an effect of a manipulated prosodic boundary immediately before the $w h$-word, Experiment 3 can tell us whether the possibility of an undetected boundary could possibly be responsible for the effects we observed in Experiments 1 and 2.

\section{Method}

Materials. The same person who recorded the Experiment 2 materials recorded four forms of each of sixteen experimental sentences (illustrated in 6) together with 38 filler sentences and seven practice sentences (similar to those used in Experiment 2). They were acoustically analyzed in the same way as in Experiments 1 and 2. The sentences and their ToBI transcriptions appear in Appendix $\mathrm{C}$, and the results of the acoustic analyses appear in Table 5.

6. a. I asked the pretty little girl /IPh/ who's COLD.

b. I asked the pretty little girl/iph/ who's COLD.

c. I asked the pretty little girl /IPh/ who is very COLD.

d. I asked the pretty little girl /iph/ who is very COLD.

The pre-boundary word ( irl) was substantially and significantly longer in the IPh than the iph condition ( $623 \mathrm{~ms}$ vs. $473 \mathrm{~ms} ; F(1,15)=205.6, p<.001)$. The fundamental frequency of this word in the short clause condition was $207 \mathrm{~Hz}$, while it was $203 \mathrm{~Hz}$ in all the other conditions. This difference, though it may be too small to have perceptual consequences, was statistically significant, as reflected in significant main effects of both length and type of boundary as well as a significant interaction between the two variables, $F(1,15)=6.48, p<.03$. The ToBI analysis verified that all sentences were produced with the intended boundary. We transcribed the IPh boundary for most items as $\mathrm{L}^{*} \mathrm{H}-\mathrm{L} \%$ or $\mathrm{H}^{*}$ $\mathrm{H}-\mathrm{L} \%$, to represent the feeling of continuation these medial boundaries give a listener and to reflect the fact that $\mathrm{F} 0$ is flat, slightly rising (after $\mathrm{L}^{*}$ ), or slightly falling (after $\mathrm{H}^{*}$ ) in them as opposed to F0 falling to near baseline as it does at the end of the sentence. 


\section{TABLE 5}

Acoustic analysis of the Experiment 3 materials

\begin{tabular}{lccc}
\hline & \multicolumn{3}{c}{ Region (illustrative words) } \\
\cline { 2 - 4 } & girl & who & cold \\
\cline { 2 - 4 } Condition & & Duration $(\mathrm{ms})$ & \\
\hline A (short clause, IPh) & 625 & 209 & 521 \\
B (short clause, iph) & 479 & 207 & 512 \\
C (long clause, IPh) & 621 & 231 & 482 \\
D (long clause, iph) & 467 & 253 & 482 \\
& & & \\
\hline A & & F0 maximum $(H z)$ & 235 \\
B & 207 & 194 & 228 \\
C & 203 & 195 & 229 \\
D & 203 & 195 & 222 \\
\hline
\end{tabular}

Note: values are means over all sentences

The Experiment 3 materials forced us to include the following copula or auxiliary (contracted or not) in the duration of the wh constituent, as in Experiment 1 (but unlike Experiment 2). The duration of who plus the following copula / auxiliary was longer in the long than the short conditions ( 242 vs. $208 \mathrm{~ms} ; F(1,15)=12.61, p<.01$ ), especially in the iph condition (interaction $F(1,15)=7.86, p<.02$ ). The F0 measures for who did not differ among conditions $(\mathrm{Fs}<1)$.

As in Experiments 1 and 2, the duration of the final adjective was greater in the short than in the long conditions (517 vs. $482 \mathrm{~ms} ; F(1,15)=18.34, p<.001$ ), and the short conditions exhibited higher F0 maxima than the long conditions (232 vs. 226ms; $F(1,15)=27.39, p<.001)$. In addition, the F0 of the final adjective was higher when an IPh preceded who than when an iph did ( $233 \mathrm{vs.} 226 \mathrm{~ms} ; F(1,15)=28.98, p<.001)$, presumably as a consequence of the pitch resetting expected in a separate intonational phrase.

One final acoustic measure was taken: The duration of the silence between the last word of the first phrase (girl in the example) and the who. This silence was always $0 \mathrm{~ms}$ long in the iph conditions, and averaged $237 \mathrm{~ms}$ in the $\mathrm{IPh}$ conditions, not differing between long and short clause conditions, $t(15)=1.36, p>.15$.

Subjects and Procedure. Forty-eight University of Massachusetts students were tested in individual half-hour sessions. The procedure was identical to Experiment 2.

\section{Results}

Table 6 presents the percentages of relative clause interpretations. As in Experiment 2, sentences with long ambiguous clauses were interpreted as containing a relative clause more often than sentences with short clauses, $F 1(1,47)=61.09 ; F 2(1,15)=65.70 ; p<.001$. Neither the effect of IPh boundary nor the interaction between boundary and length approached significance $(p>.25)$. 


\section{TABLE 6}

Percentage relative clause choices, Experiment 3

Percentage Relative Clause

Short clause, no IPh Boundary

Short clause, IPh Boundary

Long clause, no IPh Boundary

\section{Discussion}

The failure of the presence of an IPh boundary to have any measurable effect on choices is quite surprising. It contradicts our intuitions about the appropriate phrasing of restrictive relative clauses. We suspect, in retrospect, that our listeners often permitted nonrestrictive relative clauses as interpretations of the sentences they heard, and these certainly permit an IPh boundary. Given that we failed to find an effect of boundary strength with materials which clearly contrasted in this factor, the results indicate that the effects of pitch accent we observed in Experiments 1 and 2 could not plausibly be due to undetected differences in boundaries preceding an $\mathrm{H}^{*}$-accented $w h$-word and a $w h$-word without a prominent accent. However, they do seem to contradict our speculation that long ambiguous clauses set off only by an iph boundary favor relative clause interpretations because such length would encourage a speaker to produce an IPh boundary if not uttering a relative clause.

We are, unfortunately, left with no clear account of why long ambiguous clauses favor relative clause interpretations. The effect could be phonological, but need not be. We conducted Experiment 4 to obtain evidence on this point.

\section{EXPERIMENT 4}

Experiment 4 obtained interpretations of written versions of the sentences used in Experiments 1-3. Short and long versions were presented for interpretation, with no typographic indications of accent. If the preference for relative clause interpretations of long clause versions disappears, we can presumably take the preference observed in the auditory Experiments 1-3 to be prosodically based. However, if the preference remains, the possibility that it has nothing to do with prosody remains viable.

\section{Method}

Two forms of a written questionnaire were prepared. Each form contained one version of each of the 16 sentences used in Experiments 1-3. Half of the sentences in each form had short ambiguous clauses, and half long, counterbalanced across forms. Each questionnaire also contained eight additional similar sentences, four of which were strongly semantically biased in favor of the relative clause interpretation, and four in favor of an embedded question interpretation. These were included to check that subjects were paying attention and to avoid having only ambiguous sentences. The sentences were randomly ordered.

Fourteen students at the University of Massachusetts completed the written question- 
naire, being instructed to check one of two alternatives (as used in Experiments 2 and 3) as their initial interpretation of each sentence.

\section{Results}

The relative clause interpretation was given for $75 \%$ of the sentences with long ambiguous clauses, but only $43 \%$ of the sentences with short ambiguous clauses, $t 1(13)=4.67$; $t 2(15)=4.48 ; p<.001$. These numbers are remarkably similar to the percentage of relative clause choices found in Experiment 3 and in the final-word accented condition of Experiment 2. While it is possible that readers imposed different prosodic contours on the long and short versions and that the observed preference difference is still a prosodic effect, the simpler account is that the effect is not prosodic but that some other aspect of lengthening the clause favored a relative clause interpretation.

We do not know what this aspect is. One possibility is suggested by the fact that 13 of our 16 sentences had a matrix verb in the past tense but a relative clause/embedded question predicate in the present tense, specifically, a copula followed by an adjective. The embedded question interpretation of these sentences asserts that an act of communication took place in the past, concerning the identity of someone of whom an event or state holds. It may be most natural to express this state or event in the past tense, to match the matrix verb (consider Dick informed the neighbor who was mad). In the short versions, the copula was contracted, while it generally was not in the long versions. If this makes the tense of the copula particularly salient in the noncontracted (long) version, our readers (and listeners, in Experiments 1-3) may be particularly discouraged from making an embedded question interpretation of them.

Examination of the item-by-item data from the questionnaire gives some support to this conjecture. Thirteen of the 16 items showed a higher percentage of relative clause interpretations for the long than for the short clause versions. The remaining three were tied. Two of these three tied items were among the three items in which the embedded as well as the matrix verb was in the past, containing an auxiliary rather than a copula (and the third contained the adjective lazy, a persisting state which can reasonably be described in the present tense). We do not claim that this "tense clash" completely determines the choice of embedded question versus relative clause; for instance, we maintain our earlier conclusions that the location of the prominent accent can affect the choice. But it may be responsible for the persistent "length" effect we have observed.

\section{EXPERIMENT 5}

The final experiment used a different test of the basic hypothesis in 4 . It examined sentences that are ambiguous between an embedded (indirect) question interpretation (7a) and a temporal adjunct interpretation (7b).

7. a. Joshua began to wonder wHEN his girlfriend got a tattoo.

b. Joshua began to wonder when his girlfriend got a TAтTOO.

In Experiment 4, the prominently accented words had $\mathrm{L}+\mathrm{H}^{*}$ pitch accents, easily interpreted as conveying narrow and contrastive focus. A narrow focus on the $w h$-word of (7a) is consistent with it being a questioned constituent with contrastive focus (cf. when vs. why). Contrastive focus on when in a temporal adjunct is rather unlikely. In (7b), on the 


\section{TABLE 7}

Acoustic measurements (Duration, ms, and F0 maximum, Hz), Experiment 5

\begin{tabular}{lccc}
\hline & \multicolumn{3}{c}{ Region (illustrative words) } \\
\cline { 2 - 4 } & Wonder & when & tattoo \\
\cline { 2 - 4 } Condition & & Duration & \\
\hline Accent on when & 502 & 299 & 607 \\
Accent on tattoo & 425 & 224 & 710 \\
& & Pitch maximum & 171 \\
Accent on when & & 230 & 231 \\
Accent on tattoo & 171 & 175 & \\
\hline
\end{tabular}

Note: values are means over all sentences. Specific words are illustrative only

\section{TABLE 8}

Percentage embedded question, adjunct, and “other" paraphrases, Experiment 5

\begin{tabular}{lccc}
\hline & \multicolumn{3}{c}{ Measure } \\
\cline { 2 - 4 } Condition & $\begin{array}{c}\text { \% Embedded } \\
\text { question }\end{array}$ & $\begin{array}{c}\text { \% Temporal } \\
\text { adjunct }\end{array}$ & Other \\
\hline A (WHEN) & 47.6 & 35.0 & 17.4 \\
B (TATTOO) & 29.9 & 52.7 & 17.4 \\
\hline
\end{tabular}

other hand, the pitch accent falls on tattoo, which can receive contrastive focus within a temporal adjunct. Thus, embedded question interpretations of (7a) should be more frequent than of (7b).

\section{Methods}

Materials. Twelve sentences were constructed to be ambiguous between an embedded question and a temporal-adjunct interpretation, as in (7) (see Appendix D for all experimental materials and their ToBI transcriptions). A phonetically-trained linguist recorded these twelve sentences in two forms each along with 96 other sentences and 10 practice sentences. One version of each sentence contained a $\mathrm{L}+\mathrm{H}^{*}$ pitch accent on a $w h$-word (7a) but nowhere else in the final clause. The final word in these versions was unaccented. The other version (7b) contained a $\mathrm{L}+\mathrm{H}^{*}$ accent only on the final word of the final clause, and the $w h$-word received no pitch accent (apart from one when which received a $L^{*}$ accent). The versions with accented $w h$-words were predicted by (4) to favor embedded question interpretations relative to the unaccented forms.

To acoustically verify the accent manipulation, duration, and F0 maximum values were obtained for the verb, the wh-word (when), and the final content word (tattoo) and are given in Table 7. The durations of the verb and the $w h$-word were significantly longer when the $w h$-word was accented than when it was not (502 vs. $425 \mathrm{~ms}$ for the verb, $t(11)=4.58, p<.001$; 
399 versus $224 \mathrm{~ms}$ for the $w h$-word, $t(11)=9.66, p<.001)$. Duration of the final content word was longer when it was accented than when it was not, 710 versus $607 \mathrm{~ms}, t(11)=5.61$, $p<.001$. The F0 maximum on the verb did not differ between the two conditions but the F0 maximum was higher on the $w h$-word when it was accented and higher on the final content word when it was accented ( $230 \mathrm{vs.} 175 \mathrm{~Hz}$ for the $w h$-word, $t(11)=15.33, p<.001 ; 231$ versus 171 for the final content word, $t(11)=18.60, p<.001)$.

Subjects and Procedure. Forty-eight University of Massachusetts students were tested in individual 45-min sessions. The procedure was identical to that used in Experiment 1, aside from the longer (108 item) list of sentences.

\section{Results and Discussion}

Table 8 presents the mean percentages of paraphrases that indicated an embedded indirect question reading, a temporal adjunct reading, or were uninterpretable. Embedded question interpretations were more frequent when the $w h$-word was accented than when the final content word was, 47.6 versus $29.9 \%, t_{1}(47)=5.08, p<.001 ; t_{2}(11)=3.58, p<.01$. A comparable, but opposite, difference was observed for frequency of temporal adjunct paraphrases. As in Experiments 1 and 2, focus on a $w h$-word, conveyed by a pitch accent, increased the likelihood that a sentence would be interpreted as containing a question.

\section{CONCLUSIONS}

Experiments 1,2, and 5 showed that the presence of a pitch accent conveying focus can disambiguate the structure of ambiguous sentences. That pitch accents can convey focus in English is not controversial. However, there has been some dispute over whether pitch accents can resolve syntactic ambiguities. The present experiments are the first that we know of to demonstrate that the syntactic analysis of an ambiguous sentence can be disambiguated in favor of an embedded question by placing a pitch accent on the interrogative phrase. This demonstration supports the hypothesis presented in (4).

Experiment 3 showed that the presence of an iph versus an IPh boundary preceding the ambiguous phrase is not sufficient to disambiguate these sentences, at least when the most prominent accent in the ambiguous phrase is on the final content word. We interpret this result as supporting our claim that it is the location of the most salient pitch accent and not a confound of pitch accent and boundary strength that accounts for the disambiguation observed in Experiments 1, 2, and 5.

We have not demonstrated which prosodic effects result in a word being perceived as the most prominently accented word in an intermediate phrase, as our materials were produced with both $\mathrm{H}^{*}$ pitch accent and salient stress on the critical word. It is possible that other ways of making the $w h$-word perceptually prominent (e.g., by lengthening a $\mathrm{L}^{*}$ accented $w h$-word) would have similar effects. Interestingly, though, the most prominent word in our materials was not necessarily the final word in the phonological (or intermediate) phrase to carry a pitch accent. One of our speakers consistently produced sentences in which the most prominently accented word in an intermediate phrase was followed by words with $! \mathrm{H}^{*}$ or $\mathrm{L}^{*}$ pitch accents. Our intuitions and our results both suggest that the prominently accented word was interpreted as the focus of the sentence. If so, this suggests 
that our prosodic transcription systems may need to be revised to be able to reflect cases in which the final pitch accent of an intermediate phrase is not interpreted as delimiting its focus. Alternatively, if it is the case that the final pitch accent of an intermediate phrase (in English) always marks focus, our results suggest that the resolution of this syntactic ambiguity is influenced not by the location of the most prominent accented word but by the kinds of pitch accents - for example, $\mathrm{L}^{*}$ versus $\mathrm{H}^{*}$ - on key words in the sentence.

Experiments 1-4 indicated that the length of the ambiguous clause can have a substantial effect on its interpretation. Experiments 1 and 2 explored the possibility that the effect of placing a prominent pitch accent on the $w h$-word would be modulated by the length of the clause, and Experiment 3 searched for a similar interaction between length and the presence of an IPh boundary immediately before the clause in question. With the questionable exception of the percentage of relative clause paraphrases measure of Experiment 1, all our data indicated complete lack of any interaction. Experiment 4 strongly suggested that the length effect does not involve prosody; the effect appeared on a written questionnaire. We speculated that contraction of the copula in the short, but not the long, clause items might be at the root of the length effect.

Whatever it is that accounts for the length effect, we note that our results do not support the predictions of an interesting recent proposal by Fodor (1998) that "heavy" phrases are preferentially interpreted as being associated with a higher node in the syntactic tree so that they are associated with a syntactic sister of similar size. Experiments 1-4 all found the opposite effect when heaviness is viewed as length: Longer ambiguous clauses tended to be interpreted as relative clauses more than as embedded questions. Further, if we assume that an intonational phrase is heavier than an intermediate phrase, Experiment 3 found no effect of the $\mathrm{IPh} /$ iph contrast on the relative frequency of relative clause versus embedded question interpretation.

We believe that our results carry some suggestions regarding the development of an adequate general theory of prosody and its role in language comprehension. Placing a pitch accent on a function word (who or when) affects the syntactic analysis of the clause that contains it. Presumably, this effect is mediated by the assignment of focus. Research that places sentences containing ambiguous $w h$-clauses in discourses that support different patterns of focus may help elucidate when it is appropriate to place focus on an interrogative pronoun (or other function word, for that matter) and when placing focus on a function word succeeds in changing the syntactic analysis of the clause that contains it.

In addition, we believe that it will be necessary to examine the role of focus and pitch accent in interaction with other prosodic variables, with the goal of understanding how all the aspects of prosodic structure - accent, rhythm, timing, intonation, pitch range, and so forth - are involved in language comprehension. The experiments reported here searched for ways in which the effects of a pitch accent were affected by phrasal length and by intonational phrasing. They found, contrary to our expectations, a simple effect of pitch accent, unmodulated by other prosodic factors. However, we continue to believe that the effects of prosody on language comprehension will best be understood by viewing the listener as constructing and using a full prosodic description of a heard utterance (Schafer, 1997), a view that encourages the possibility that superficially different aspects of prosody will have mutually-interacting influences on sentence interpretation. 
Received: August 11, 1998; revised manuscript received: February 19, 1999; accepted: October 20, 1999

\section{REFERENCES}

BECKMAN, M. E., \& HIRSCHBERG, J. (1994). The ToBI annotation conventions. Columbus, OH: Ohio State University.

BECKMAN, M. E., \& PIERREHUMBERT, J. B. (1986). Intonationalstructure in Japanese and English. Phonology, 3, 255-309.

CARLSON, K. (submitted). The effects of parallelismand prosody in the processing of gapping structures.

CUTLER, A., DAHAN, D., \& DONSELAAR, W. van (1997). Prosody in the comprehension of spoken language: A literature review. Language and Speech, 40, 141-201.

FODOR, J. D. (1998). Learning to parse? Journal of Psycholinguistic Research, 27, 285-319.

GEE, J., \& GROSJEAN, F. (1983). Performance structure: A psycholinguistic and linguistic appraisal. Cognitive Psychology, 15, 411-458.

JUN S-A. (1993). The phonetics and phonology of Korean prosody. Unpublished doctoral dissertation. The Ohio State University.

JUN S-A., \& OH, M. (1996). A prosodic analysis of three types of $w h$-phrases in Korean. Language and Speech, 40, 37-61.

KJELGAARD, M. M., \& SPEER, S. R. (1999). Prosodic facilitation and interference in the resolution of temporary syntactic closure ambiguity. Journal of Memory and Language, 40, 153-194.

LADD, D. R. (1996). Intonationalphonology. Cambridge, U.K.: Cambridge University Press.

LEHISTE, I. (1973). Phonetic disambiguation of syntactic ambiguity. Glossa, 7, 107-122.

LIBERMAN, M., \& PRINCE, A. (1977). On stress and linguistic rhythm. Linguistic Inquiry, 8, 249-336.

NESPOR, M., \& VOGEL, I. (1989). On clashes and lapses. Phonology, 6, 69-116.

PIERREHUMBERT, J., \& BECKMAN, M. (1988). Japanese tone structure. Cambridge, MA: MIT Press.

PIERREHUMBERT, J. B. (1980). The phonology and phonetics of English intonation. Doctoral dissertation, MIT. (Bloomington, IN: Indiana University Linguistics Club).

PIERREHUMBERT, J. B., \& HIRSCHBERG, J. (1990). The meaning of intonational contours in the interpretationof discourse.In P. R. Cohen, J. Morgan, \& M. E. Pollack (Eds.), Intentions in communication (pp. 271-311). Cambridge, MA: MIT Press.

PRICE, P. J., OSTENDORF, M., SHATTUCK-HUFFNAGEL, S., \& FONG, C. (1991). The use of prosody in syntactic disambiguation.Journal of the Acoustical Society of America, 90, 2956-2970.

SCHAFER, A. (1997). Prosodic parsing:The role of prosody in sentence comprehension. Doctoral dissertation, University of Massachusetts, Amherst, MA: GLSA.

SCHAFER, A., CARTER, J., CLIFTON, C., Jr., , \& FRAZIER, L. (1996). Focus in relative clause construal. Language and Cognitive Processes, 11, 135-163.

SELKIRK, E. (1984). Phonology and syntax: The relation between sound and structure. Cambridge, MA: MIT Press.

SELKIRK, E. O. (1995). Sentence prosody: Intonation, stress, and phrasing. In J. Goldsmith (Ed.), Handbook of phonological theory (pp.550-569). Oxford: Blackwell.

SILVERMAN, K., BECKMAN, M. E., PITRELLI, J., OSTENDORF, M., WIGHTMAN, C., PRICE, P., PIERREHUMBERT, J., \& HIRSCHBERG, J. (1992). ToBI: A standard for labeling English prosody. Paper presented at the Second InternationalConference on Spoken Language Processing, Banff, Canada.

SPEER, S. R., CROWDER, R. G., \& THOMAS, L. M. (1993). Prosodic structure and sentence recognition. Journal of Memory and Language, 32, 336-358.

SPEER, S. R., KJELGAARD, M. M., \& DOBROTH, K. M. (1996). The influence of prosodic structure on the resolution of temporary syntactic closure ambiguities.Journal of PsycholinguisticResearch, 25, 249-272. 
WARREN, P., GRABE, E., \& NOLAN, F. (1995). Prosody, phonology, and parsing in closure ambiguities. Language and Cognitive Processes, 10, 457-486.

\section{APPENDIX A}

Sentences used in Experiment 1 . Most prominently accented words indicated in uppercase. $\mathrm{H}^{*}, \mathrm{~L}^{*}$, $\mathrm{L}+\mathrm{H}^{*}=$ high, low, and low-plus-high pitch accents; ! $\mathrm{H}^{*}=$ downstepped high pitch accent; H-, L$=$ high and low phrase accents; $\mathrm{L} \%=$ low boundary tone.

\section{$\mathrm{L}^{*} \mathrm{~L}-\quad \mathrm{L}^{*} \quad \mathrm{~L}^{*} \quad \mathrm{~L}^{*} \mathrm{~L}-\mathrm{H}^{*} \quad \mathrm{~L}-\mathrm{L} \%$}

1a. I asked the pretty little girl wHO's cold.
$\mathrm{L}^{*}$
$\mathrm{L}^{*}$
$\mathrm{L}^{*} \mathrm{~L}-\quad \mathrm{L}^{*} \quad \mathrm{H}^{*} \mathrm{~L}-\mathrm{L} \%$

1b. I asked the pretty little girl who's COLD.
L* L-
$L^{*} \quad L^{*}$
L*L- $\quad \mathrm{H}^{*} \quad ! \mathrm{H}^{*} \quad ! \mathrm{H}^{*} \quad \mathrm{~L}-\mathrm{L} \%$

1c. I asked the pretty little girl wHO is very cold.
L* L-
$L^{*} \quad L^{*} \quad L^{*} \mathrm{~L}-\mathrm{L}^{*} \quad \mathrm{~L}^{*}$
$\mathrm{H}^{*} \quad \mathrm{~L}-\mathrm{L} \%$

1d. I asked the pretty little girl who is very COLD.

$\mathrm{L}^{*} \quad \mathrm{~L}^{*} \quad \mathrm{H}-\quad \mathrm{H}^{*} \quad \mathrm{~L}-\mathrm{L} \%$

2a. Mary told the gentle-looking visitor wHO's old.
$\mathrm{L}^{*}$
$\mathrm{L}^{*}$
$\mathrm{H}^{-} \quad \mathrm{L}^{*} \quad \mathrm{H}^{*} \mathrm{~L}-\mathrm{L} \%$

2b. Mary told the gentle-looking visitor who's OLD.
$\mathrm{L}^{*}$
$\mathrm{L}^{*}$
$\mathrm{H}-\mathrm{H}^{*} \quad ! \mathrm{H}^{*}$
!H* L-L\%

2c. Mary told the gentle-looking visitor wHO is already quite old.
$\mathrm{L}^{*}$
$\mathrm{L}^{*}$
$\mathrm{H}-\mathrm{L}^{*} \quad \mathrm{~L}^{*}$
$\mathrm{H}^{*} \mathrm{~L}-\mathrm{L} \%$

2d. Mary told the gentle-looking visitor who is already quite OLD.
$\mathrm{L}^{*} \quad$ L- $\mathrm{L}^{*}$
$\mathrm{L}^{*} \mathrm{~L}-\quad \mathrm{H}^{*}$
$\mathrm{L}-\mathrm{L} \%$

3a. Barbara informed the official wHO's drunk.
L* L- L*
$\mathrm{L}^{*} \mathrm{~L}-$
$\mathrm{L}^{*} \quad \mathrm{H}^{*} \mathrm{~L}-\mathrm{L} \%$

3b. Barbara informed the official who's DRUNK.
$\mathrm{L}^{*} \quad$ L- $\mathrm{L}^{*} \mathrm{~L}-$
$L^{*} \mathrm{~L}-\quad \mathrm{H}^{*} \quad !^{*}$
! H* L-L\%

3c. Barbara informed the official wHO is publicly drunk.
L* L- L* L-
$\mathrm{L}^{*} \mathrm{~L}-\quad \mathrm{L}^{*}$
$\mathrm{H}^{*} \mathrm{~L}-\mathrm{L} \%$

3d. Barbara informed the official who is publicly DRUNK.
$\mathrm{L}^{*}$
$\mathrm{H}-\mathrm{H}^{*}$
L-L\%

4a. Edgar showed the teacher wHO's new.

4b. Edgar showed the teacher who's NEw.

$$
\text { L- } \quad \mathrm{L}^{*}, \mathrm{H}^{*} \mathrm{~L}-\mathrm{L} \%
$$
$\mathrm{L}^{*}$
$\mathrm{H}-\mathrm{H}^{*}$
L-L\%

4c. Edgar showed the teacher wHO is completely new.
$L^{*}$
L- $\mathrm{L}^{*}$
$\mathrm{H}^{*} \mathrm{~L}-\mathrm{L} \%$

4d. Edgar showed the teacher who is completely NEW.

$$
\mathrm{L}^{*} \quad \mathrm{~L}^{*} \quad \mathrm{~L}-\mathrm{L}^{*} \quad \mathrm{~L}^{*} \mathrm{H}-\mathrm{H}^{*}
$$

5a. The mysterious spectator taught the player wHO's good.

5b. The mysterious spectator taught the player who's GOOD. 


$$
\mathrm{L}^{*} \quad \mathrm{~L}^{*} \quad \mathrm{~L}-\mathrm{L}^{*} \quad \mathrm{~L}-\mathrm{H}^{*} \quad \mathrm{H}^{*} \quad \mathrm{H}^{*} \quad \mathrm{~L}-\mathrm{L} \%
$$

5c. The mysterious spectator taught the player wHO is exceptionally good.

$$
\mathrm{L}^{*} \quad \mathrm{~L}^{*} \quad \mathrm{~L}_{-} \mathrm{L}^{*} \quad \mathrm{~L}^{*} \mathrm{~L}^{*} \quad \mathrm{~L}^{*} \quad \mathrm{H}^{*} \quad \mathrm{~L}-\mathrm{L} \%
$$

5d. The mysterious spectator taught the player who is exceptionally GOOD.

\section{$\mathrm{L}^{*} \quad$ L- $\mathrm{H}^{*} \quad$ L-L\%}

6a. Dick informed the neighbor whO's mad.

6b. Dick informed the neighbor who's MAD.
$L^{*}$
L- $\mathrm{H}^{*} \quad \mathrm{H}^{*}$
! H* L-L\%

6c. Dick informed the neighbor wHO is clearly mad.
$L^{*}$
L- $\mathrm{L}^{*}$
$\mathrm{H}^{*} \mathrm{~L}-\mathrm{L} \%$

6d. Dick informed the neighbor who is clearly MAD.
$\mathrm{L}^{*} \mathrm{~L}-\mathrm{L}^{*}$
$\mathrm{L}^{*} \mathrm{~L}-$
L-L\%

7a. Sam reported to the editor wHO's pregnant.
$\mathrm{L}^{*} \mathrm{~L}-\mathrm{L}^{*}$
$\mathrm{L}^{*} \mathrm{~L}$
$\mathrm{L}^{*} \mathrm{H}^{*}$
L-L\%

7b. Sam reported to the editor who's pregnant.
$\mathrm{L}^{*} \mathrm{~L}-\mathrm{L}^{*}$
$\mathrm{L}^{*} \mathrm{~L}-$
$\mathrm{H}^{*}$
! $\mathrm{H}^{*}$
$! H^{*}$
$\mathrm{L}-\mathrm{L} \%$

7c. Sam reported to the editor wHO is extremely pregnant.
$\mathrm{L}^{*} \mathrm{~L}-\mathrm{L}^{*}$
$\mathrm{L}^{*} \mathrm{~L}-$
$L^{*}$
$\mathrm{H}^{*} \quad \mathrm{~L}-\mathrm{L} \%$

7d. Sam reported to the editor who is extremely PREGNANT.

$$
\mathrm{L}^{*} \quad \mathrm{~L}-\mathrm{L}^{*} \quad \mathrm{~L}-\mathrm{H}^{*} \quad \mathrm{~L}-\mathrm{L} \%
$$

8a. The counselor whispered to the student wHO's mean.

$$
\mathrm{L}^{*} \quad \mathrm{~L}^{-} \mathrm{L}^{*} \quad \mathrm{~L}^{*} \mathrm{~L}-\mathrm{H}, \mathrm{H}^{*} \mathrm{~L}-\mathrm{L} \%
$$

8b. The counselor whispered to the student who's MEAN.

$$
\mathrm{L}^{*} \quad \mathrm{~L}-\mathrm{L}^{*} \quad \mathrm{~L}^{*} \mathrm{~L}-\mathrm{H}^{*} ! \mathrm{H}^{*} \quad ! \mathrm{H}^{*} \mathrm{~L}-\mathrm{L} \%
$$

8c. The counselor whispered to the student WHO is always mean.

$$
\mathrm{L}^{*} \quad \mathrm{~L}-\mathrm{L}^{*} \quad \mathrm{~L}^{*} \mathrm{~L}-\mathrm{L}^{*} \mathrm{~L}^{*} \quad \mathrm{H}^{*} \mathrm{~L}-\mathrm{L} \%
$$

8d. The counselor whispered to the student who is always MEAN.
$\mathrm{L}^{*} \quad$ L- $\mathrm{L}^{*}$
$\mathrm{L}^{*} \quad \mathrm{~L}-\mathrm{H}^{*}$
L-L\%

9a. Elizabeth shouted to the fireman wHO fainted.
L* L- L*
$L^{*} \quad L-\quad L^{*} H^{*}$
L-L\%

9b. Elizabeth shouted to the fireman who FAINTED.
$\mathrm{L}^{*} \quad \mathrm{~L}-\mathrm{L}^{*}$
$\mathrm{L}^{*} \quad \mathrm{~L}-\mathrm{H}^{*}$
L-L\%

9c. Elizabeth shouted to the fireman wHO had just fainted.
L* L- L*
$L^{*} \quad \mathrm{~L}-$
$\mathrm{H}^{*}$
L-L\%

9d. Elizabeth shouted to the fireman who had just FAINTED.
$\mathrm{L}^{*} \mathrm{H}-\mathrm{L}^{*}$
$\mathrm{L}^{*} \mathrm{H}-\quad \mathrm{H}^{*}$
$\mathrm{L}-\mathrm{L} \%$

10a. Paula asked the waiter wHO arrived.
$\mathrm{L}^{*} \mathrm{H}-\mathrm{L}^{*}$
$\mathrm{L}^{*} \mathrm{H}-\quad \mathrm{L}$
$\mathrm{L}^{*} \quad \mathrm{H}^{*} \quad \mathrm{~L}-\mathrm{L} \%$

10b. Paula asked the waiter who ARRIVED.
$\mathrm{L}^{*} \mathrm{H}-\mathrm{L}^{*}$
$\mathrm{L}^{*} \mathrm{H}$
$\mathrm{H}^{*} \quad \mathrm{~L}^{*}$
L-L\%

10c. Paula asked the waiter wHO had just arrived.

$\mathrm{L}^{*} \mathrm{H}-\mathrm{L}^{*}$

$\mathrm{L}^{*} \mathrm{H}-$

$\mathrm{L}^{*}$

10d. Paula asked the waiter who had just ARRIVED. 


$$
\mathrm{L}^{*} \mathrm{H}-\quad \mathrm{L}^{*} \quad \mathrm{H}-\mathrm{H}^{*} \quad \mathrm{~L}-\mathrm{L} \%
$$

11a. The children told the babysitter wHO's nice.

$$
L^{*} \mathrm{H}-\quad \mathrm{L}^{*} \quad \mathrm{H}-\quad \mathrm{L}^{*} \quad \mathrm{H}^{*} \mathrm{~L}-\mathrm{L} \%
$$

11b. The children told the babysitter who's NICE.

$$
L^{*} \mathrm{H}-\quad \mathrm{L}^{*} \quad \mathrm{H}-\quad \mathrm{H}^{*} ! \mathrm{H}^{*} \quad ! \mathrm{H}^{*} \mathrm{~L}-\mathrm{L} \%
$$

11c. The children told the babysitter wHO is always so nice.

$$
\mathrm{L}^{*} \mathrm{H}-\mathrm{L}-\mathrm{H}-\mathrm{H} \mathrm{L}^{*} \quad \mathrm{H}^{*} \mathrm{~L}-\mathrm{L} \%
$$

11d. The children told the babysitter who is always so NICE.

$$
\mathrm{L}^{*} \mathrm{H}-\mathrm{L} \quad \mathrm{L}{ }^{*} \quad \mathrm{H}_{-}^{*} \quad \mathrm{~L}-\mathrm{L} \%
$$

12a. The producer informed the actress whо's late.

$$
\text { L*H- } \quad L^{*} \quad H-\quad L^{*} \quad H^{*} \quad \text { L-L\% }
$$

12b. The producer informed the actress who's LATE.

$$
\mathrm{L}^{*} \mathrm{H}-\quad \mathrm{L}^{*} \quad \mathrm{H}-\quad \mathrm{H}^{*} \quad \mathrm{H}^{*} \quad ! \mathrm{H}^{*} \mathrm{~L}-\mathrm{L} \%
$$

12c. The producer informed the actress WHO is typically late.

$$
\mathrm{L}^{*} \mathrm{H}-\mathrm{L} \quad \mathrm{L} \text { - } \mathrm{L}^{*} \quad \mathrm{H}^{*} \mathrm{~L}-\mathrm{L} \%
$$

12d. The producer informed the actress who is typically LATE.
$\mathrm{L}^{*} \mathrm{H}-\mathrm{L}^{*}$
$\mathrm{L}^{*} \mathrm{~L}-\mathrm{H}^{*}$
L-L\%

13a. Sally taught the tourist wHO's weird.
L*H- L*
$L^{*} \quad L_{-} \quad L^{*} \quad \mathrm{H}^{*} \quad \mathrm{~L}-\mathrm{L} \%$

13b. Sally taught the tourist who's WEIRD.

$$
\text { L*L- L* } \quad \mathrm{L}^{*} \quad \mathrm{~L}-\mathrm{H}^{*} \quad \mathrm{H}^{*} \quad ! \mathrm{H}^{*} \quad \mathrm{~L}-\mathrm{L} \%
$$

13c. Sally taught the tourist WHO is really weird.
L*L- L*
$\mathrm{L}^{*} \mathrm{~L}-\mathrm{L}^{*}$
$\mathrm{H}^{*} \quad \mathrm{~L}-\mathrm{L} \%$

13d. Sally taught the tourist who is really WEIRD.
$L^{*}$ L- L*
$\mathrm{L}^{*} \quad \mathrm{H}$
$\mathrm{H}-\quad \mathrm{H}^{*}$
L-L\%

14a. Paul reported to the supervisor WHO's lazy.
$\mathrm{L}^{*} \mathrm{~L}-\mathrm{L}^{*}$
$L^{*}$
H- $\quad L^{*} \quad \mathrm{H}^{*} \quad \mathrm{~L}-\mathrm{L} \%$

14b. Paul reported to the supervisor who's LAZY.
$\mathrm{L}^{*} \mathrm{~L}-\mathrm{L}^{*}$
$L^{*}$
H- $\mathrm{H}^{*}$
L-L\%

14c. Paul reported to the supervisor whO is always lazy.
$\mathrm{L}^{*} \mathrm{~L}-\mathrm{L}^{*}$
$\mathrm{L}^{*} \quad \mathrm{H}-\mathrm{L}^{*}$
$\mathrm{H}^{*} \mathrm{~L}-\mathrm{L} \%$

14d. Paul reported to the supervisor who is always LAZY.
$\mathrm{L}^{*} \quad \mathrm{H}-\mathrm{L}^{*}$
$L^{*}$
L- $\quad \mathrm{H}^{*}$
L-L\%

15a. Lawrence signaled to the photographer wHo blinked.
$\mathrm{L}^{*} \quad \mathrm{H}-\mathrm{L}^{*}$
$\mathrm{L}^{*}$
$\mathrm{H}$ -
$\mathrm{L}^{*} \mathrm{H}^{*} \quad \mathrm{~L}-\mathrm{L} \%$

15b. Lawrence signaled to the photographer who BLINKED.
$\mathrm{L}^{*} \quad \mathrm{H}-\mathrm{L}^{*}$
L*
L- $\quad \mathrm{H}^{*}$
$\mathrm{L}^{*} \quad \mathrm{~L}-\mathrm{L} \%$

15c. Lawrence signaled to the photographer wHO had just blinked.
$\mathrm{L}^{*} \quad \mathrm{H}-\mathrm{L}^{*}$
$L^{*}$
$\mathrm{H}$ - $\quad \mathrm{L}^{*}$
$\mathrm{H}^{*} \quad \mathrm{~L}-\mathrm{L} \%$

15d. Lawrence signaled to the photographer who had just BLINKED.

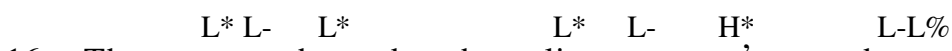

16a. The reporter shouted to the policeman wHO's armed.

$$
\mathrm{L}^{*} \mathrm{~L}-\mathrm{L}^{*} \quad \mathrm{~L}^{*} \quad \mathrm{~L}-\quad \mathrm{L}^{*} \mathrm{H}^{*} \quad \mathrm{~L}-\mathrm{L} \%
$$

16b. The reporter shouted to the policeman who's ARMED. 


$$
\mathrm{L}^{*} \mathrm{~L}-\quad \mathrm{L}^{*} \quad \mathrm{~L}^{*} \quad \mathrm{~L}-\quad \mathrm{H}^{*} \quad \mathrm{H}^{*} \quad \mathrm{H}^{*} \quad \mathrm{~L}-\mathrm{L} \%
$$

16c. The reporter shouted to the policeman WHO is heavily armed.

$$
\mathrm{L}^{*} \mathrm{~L}-\mathrm{L}^{*} \quad \mathrm{~L}^{*} \quad \mathrm{~L}-\mathrm{L}^{*} \quad \mathrm{~L}^{*} \quad \mathrm{H}^{*} \quad \mathrm{~L}-\mathrm{L} \%
$$

16d. The reporter shouted to the policeman who is heavily ARMED.

\section{APPENDIX B}

Sentences used in Experiment 2. Most prominently accented words indicated in uppercase. $\mathrm{H}^{*}, \mathrm{~L}^{*}$, $\mathrm{L}+\mathrm{H}^{*}=$ high, low, and low-plus-high pitch accents; ! $\mathrm{H}^{*}=$ downstepped high pitch accent; H-, L=high and low phrase accents; $\mathrm{L} \%=$ low boundary tone.

\section{$\mathrm{L}^{*} \mathrm{H}-\mathrm{L} \% \quad \mathrm{~L}^{*} \quad \mathrm{~L}^{*} \quad \mathrm{~L}^{*} \mathrm{~L}-\mathrm{L} \% \quad \mathrm{H}^{*} \quad \mathrm{~L}-\mathrm{L} \%$}

1a. I asked the pretty little girl wHO's cold.
$\mathrm{L} * \mathrm{~L}-\mathrm{H} \%$
$L^{*} \quad L^{*} \quad L^{*} L_{-} \quad L^{*} \quad H^{*} \quad L-L \%$

1b. I asked the pretty little girl who's COLD.
L*L-H\%
$L^{*} \quad L^{*} \quad L^{*} L-H^{*}$
$\mathrm{L}-\mathrm{L} \%$

1c. I asked the pretty little girl wHO is very cold.
$\mathrm{L} * \mathrm{H}-\mathrm{L} \%$
$\mathrm{L}^{*} \quad \mathrm{~L}^{*} \quad \mathrm{~L}^{*} \mathrm{~L}-\mathrm{L}^{*}$
$\mathrm{H}^{*} \mathrm{~L}-\mathrm{L} \%$

1d. I asked the pretty little girl who is very COLD.
$\mathrm{H} * \mathrm{H}-\mathrm{L} * \mathrm{~L}-$
$\mathrm{H}^{*}$
$\mathrm{L}^{*} \mathrm{~L}-$
$\mathrm{H}^{*} \quad \mathrm{~L}-\mathrm{L} \%$

2a. Mary told the gentle-looking visitor wHO's old.
L* L*L-
$\mathrm{L}^{*}$
$\mathrm{L}^{*} \mathrm{~L}$ -
$\mathrm{H}^{*} \quad \mathrm{~L}-\mathrm{L} \%$

2b. Mary told the gentle-looking visitor who's OLD.
$\mathrm{L}^{*} \quad \mathrm{~L}^{*} \mathrm{~L}-$
$\mathrm{H}^{*}$
$\mathrm{L}^{*} \mathrm{~L}-$
$\mathrm{H}^{*}$
L-L\%

2c. Mary told the gentle-looking visitor wHO is already quite old.
L* $\quad$ L*L-
$\mathrm{L}^{*}$
$\mathrm{L}^{*} \mathrm{~L}-$
$\mathrm{L}^{*} \quad \mathrm{~L}^{*}$
$\mathrm{H}^{*} \quad \mathrm{~L}-\mathrm{L} \%$

2d. Mary told the gentle-looking visitor who is already quite OLD.
$\mathrm{L}^{*} \mathrm{~L}-$
L* L-
$\mathrm{L}^{*} \mathrm{~L}-\mathrm{H}^{*}$
$\mathrm{L}-\mathrm{L} \%$

3a. Barbara informed the official wHO's drunk.
$\mathrm{L}^{*} \quad \mathrm{~L}-\quad \mathrm{L}^{*} \mathrm{~L}-$
$\mathrm{L}^{*} \mathrm{~L}-$
$\mathrm{H}^{*} \quad \mathrm{~L}-\mathrm{L} \%$

3b. Barbara informed the official who's DRUNK.
L* L- L* L-
$\mathrm{L}^{*} \mathrm{~L}-\mathrm{H}^{*}$
$\mathrm{L}-\mathrm{L} \%$

3c. Barbara informed the official wHO is publicly drunk.
L* L- L* L-
$\mathrm{L}^{*} \mathrm{~L}$ -
$\mathrm{L}^{*}$
$\mathrm{H}^{*} \quad \mathrm{~L}-\mathrm{L} \%$

3d. Barbara informed the official who is publicly DRUNK.
$\mathrm{L}^{*} \mathrm{~L}-\mathrm{L}$ - L-
$\mathrm{L}^{*} \mathrm{~L}-$
$\mathrm{H}^{*}$
L-L\%

4a. Edgar showed the teacher wHO's new.
L* L-
$\mathrm{L}^{*} \mathrm{~L}-$
$\mathrm{L}^{*} \mathrm{~L}-$
$\mathrm{H}^{*} \mathrm{~L}-\mathrm{L} \%$

4b. Edgar showed the teacher who's NEw.
L* L- L* L-
$\mathrm{L}^{*} \mathrm{~L}-$
$\mathrm{H}^{*}$
L-L\%

4c. Edgar showed the teacher wHO is completely new.
$\mathrm{L}^{*} \mathrm{~L}-\mathrm{L}^{*} \mathrm{~L}-$
$\mathrm{L}^{*} \mathrm{~L}-$
$\mathrm{L}^{*}$
$\mathrm{L}^{*} \quad \mathrm{H}^{*} \mathrm{~L}-\mathrm{L} \%$

4d. Edgar showed the teacher who is completely NEW.

$$
\mathrm{L}^{*} \quad \mathrm{~L}^{*} \mathrm{~L}-\mathrm{L}^{*} \quad \mathrm{~L}^{*} \mathrm{~L}-\mathrm{H}^{*}
$$

5a. The mysterious spectator taught the player wHO's good. 


\section{$\mathrm{L}^{*} \quad \mathrm{~L}^{*} \quad \mathrm{~L}-\mathrm{L}^{*} \quad \mathrm{~L}-\mathrm{L}^{*} \quad \mathrm{H}^{*} \mathrm{~L}-\mathrm{L} \%$}

5b. The mysterious spectator taught the player who's GOOD.

$$
\mathrm{L}^{*} \quad \mathrm{~L}^{*} \mathrm{~L}-\mathrm{L}^{*} \quad \mathrm{~L}-\mathrm{H}^{*}
$$

5c. The mysterious spectator taught the player wHO is exceptionally good.

$$
\mathrm{L}^{*} \quad \mathrm{~L}^{*} \mathrm{~L}-\mathrm{L}^{*} \quad \mathrm{~L}-\mathrm{L}^{*} \quad \mathrm{~L}^{*} \quad \mathrm{H}^{*} \mathrm{~L}-\mathrm{L} \%
$$

5d. The mysterious spectator taught the player who is exceptionally GOOD.

$$
\mathrm{L}^{*} \quad \text { L- } \quad \mathrm{L}^{*} \quad \mathrm{~L}-\quad \mathrm{H}^{*} \quad \text { L-L\% }
$$

6a. Dick informed the neighbor wHo's mad.

$$
L^{*} \text { L- L* L- , H* L-L\% }
$$

6b. Dick informed the neighbor who's MAD.

$$
\mathrm{L}^{*} \quad \text { L- } \quad \mathrm{L}^{*} \quad \mathrm{~L}-\mathrm{H}^{*}
$$

6c. Dick informed the neighbor wHO is clearly mad.

$$
\mathrm{L}^{*} \text { L- } \quad \mathrm{L}^{*} \quad \mathrm{~L}-\mathrm{L}^{*} \quad \mathrm{H}^{*} \mathrm{~L}-\mathrm{L} \%
$$

6d. Dick informed the neighbor who is clearly MAD.
$\mathrm{H}^{*} \mathrm{H}-\mathrm{L}^{*} \mathrm{~L}-$
$\mathrm{L}^{*} \mathrm{~L}-\mathrm{H}^{*}$
$\mathrm{L}-\mathrm{L} \%$

7a. Sam reported to the editor WHO's pregnant.
$\mathrm{H}^{*} \mathrm{H}-\mathrm{L}^{*} \mathrm{~L}-$
$\mathrm{L}^{*} \mathrm{~L}-$
$\mathrm{H}^{*} \quad \mathrm{~L}-\mathrm{L} \%$

7b. Sam reported to the editor who's PREgnant.
$\mathrm{L}^{*} \mathrm{~L}-\mathrm{L} * \mathrm{~L}-$
$\mathrm{L}^{*} \mathrm{~L}-\mathrm{H}^{*}$
L-L\%

7c. Sam reported to the editor wHO is extremely pregnant.
L*L- L* L-
$\mathrm{L}^{*} \mathrm{~L}-$
$\mathrm{L}^{*}$
$\mathrm{H}^{*} \quad \mathrm{~L}-\mathrm{L} \%$

7d. Sam reported to the editor who is extremely PREGNANT.

$$
\mathrm{L}^{*} \quad \text { L- } \mathrm{L}^{*} \quad \mathrm{~L}-\quad \mathrm{L}^{*} \mathrm{~L}-\mathrm{H}^{*} \quad \mathrm{~L}-\mathrm{L} \%
$$

8a. The counselor whispered to the student wHO's mean.

$$
\mathrm{L}^{*} \quad \mathrm{~L}-\mathrm{L}^{*} \quad \mathrm{~L}-\quad \mathrm{L}^{*} \mathrm{~L}-\mathrm{L}^{*} \quad \mathrm{H}^{*} \quad \mathrm{~L}-\mathrm{L} \%
$$

8b. The counselor whispered to the student who's MEAN.

$$
\mathrm{L}^{*} \quad \mathrm{~L}-\quad \mathrm{L}^{*} \quad \mathrm{~L}-\quad \mathrm{L}^{*} \mathrm{~L}-\mathrm{H}^{*} \quad \mathrm{~L}-\mathrm{L} \%
$$

8c. The counselor whispered to the student wHO is always mean.

8d. The counselor whispered to the student who is always MEAN.

$$
\mathrm{L}^{*} \quad \mathrm{~L}-\quad \mathrm{L}^{*} \quad \mathrm{~L}-\quad \mathrm{L}^{*} \quad \mathrm{~L}-\mathrm{L}^{*} \quad \mathrm{~L}^{*} \quad \mathrm{H}^{*} \quad \mathrm{~L}-\mathrm{L} \%
$$

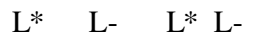
$\mathrm{L}^{*} \quad \mathrm{~L}-\mathrm{H}^{*}$
L-L\%

9a. Elizabeth shouted to the fireman wHo fainted.

$$
\text { L }^{*} \quad \text { L- L* L- } \quad \text { L* }^{*} \text { L- } \quad \mathrm{H}^{*} \mathrm{~L}-\mathrm{L} \%
$$

9b. Elizabeth shouted to the fireman who FAINTED.

$$
\text { L }^{*} \quad \text { L- L* L- } \quad \text { L }^{*} \text { L- } \mathrm{H}^{*}
$$

9c. Elizabeth shouted to the fireman wHO had just fainted.
L $^{*} \quad$ L- $\quad$ L* L-
$\mathrm{L}^{*} \mathrm{~L}-$
$\mathrm{H}^{*} \quad \mathrm{~L}-\mathrm{L} \%$

9d. Elizabeth shouted to the fireman who had just FAINTED.
$\mathrm{H}^{*} \mathrm{~L}-\mathrm{L}$ *H-L\%
$\mathrm{L}^{*} \mathrm{~L}-\mathrm{H}^{*}$
L-L\%

10a. Paula asked the waiter wHO arrived.

$$
L^{*} L-L * H-L \% \quad L^{*} L-\quad L^{*} \quad H^{*} \quad \text { L-L\% }
$$

10b. Paula asked the waiter who ARRIVED.

$$
L^{*} \text { L- L*H-L\% L L L- } \mathrm{H}^{*}
$$

10c. Paula asked the waiter wHO had just arrived. 
L* L- L*H-L\% L* L- L* $\mathrm{H}^{*} \quad$ L-L\%

10d. Paula asked the waiter who had just ARRIVED.

$$
\mathrm{H}^{*} \mathrm{H}-\mathrm{L}^{*} \mathrm{~L}-\quad \mathrm{L}^{*} \quad \mathrm{~L}^{*} \mathrm{~L}-\quad \mathrm{H}^{*} \quad \mathrm{~L}-\mathrm{L} \%
$$

11a. The children told the babysitter WHO's nice.

$$
\text { L* H- L*L- L* L*L- L* } \mathrm{H}^{*} \mathrm{~L}-\mathrm{L} \%
$$

11b. The children told the babysitter who's NICE.

$$
\mathrm{L}^{*} \mathrm{H}-\mathrm{L}^{*} \quad \mathrm{~L}^{*} \quad \mathrm{~L}^{*} \mathrm{~L}-\mathrm{H}^{*} \quad \mathrm{~L}-\mathrm{L} \%
$$

11c. The children told the babysitter WHO is always so nice.

$$
\mathrm{H}^{*} \mathrm{~L}-\mathrm{L}^{*} \quad \mathrm{~L}^{*} \mathrm{~L}^{*} \mathrm{~L}-\quad \mathrm{L}^{*} \quad \mathrm{H}^{*} \mathrm{~L}-\mathrm{L} \%
$$

11d. The children told the babysitter who is always so NICE.

$$
\mathrm{L}^{*} \mathrm{~L}-\quad \mathrm{L}^{*} \mathrm{~L}-\quad \mathrm{L}^{*} \quad \mathrm{~L}-\mathrm{H}^{*} \quad \mathrm{~L}-\mathrm{L} \%
$$

12a. The producer informed the actress WHO's late.

$$
\mathrm{L}^{*} \mathrm{~L}-\quad \mathrm{L}^{*} \mathrm{~L}-\quad \mathrm{L}^{*} \mathrm{~L}-
$$

$\mathrm{H}^{*} \mathrm{~L}-\mathrm{L} \%$

12b. The producer informed the actress who's LATE.

$$
\mathrm{L}^{*} \mathrm{~L}-\mathrm{L}^{*} \quad \mathrm{~L}^{*} \mathrm{~L}-\mathrm{H}^{*} \quad \mathrm{~L}-\mathrm{L} \%
$$

12c. The producer informed the actress WHO is typically late.

$$
\mathrm{L}^{*} \mathrm{~L}-\quad \mathrm{L}^{*} \mathrm{~L}-\quad \mathrm{L}^{*} \quad \mathrm{~L}-\quad \mathrm{L}^{*} \quad \mathrm{H}^{*} \mathrm{~L}-\mathrm{L} \%
$$

12d. The producer informed the actress who is typically LATE.

$$
\mathrm{H}^{*} \mathrm{~L}-\mathrm{L}^{*} \quad \mathrm{~L}-\quad \mathrm{L}^{*} \mathrm{~L}-\mathrm{H}^{*} \quad \text { L-L\% }
$$

13a. Sally taught the tourist WHO's weird.

$$
\text { L*L- L* L* L- L* } \mathrm{H}^{*} \quad \text { L-L\% }
$$

13b. Sally taught the tourist who's WEIRD.
$\mathrm{L}^{*} \mathrm{~L}-\mathrm{L}^{*}$
$\mathrm{L}^{*} \mathrm{~L}-\mathrm{H}^{*}$
$\mathrm{L}-\mathrm{L} \%$

13c. Sally taught the tourist WHO is really weird.

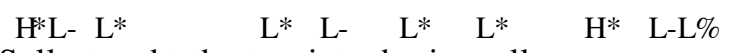

13d. Sally taught the tourist who is really WEIRD.

$$
\mathrm{H}^{*} \mathrm{~L}-\mathrm{H}^{*} \mathrm{~L}-\quad \mathrm{H}^{*} \quad \mathrm{~L}-\mathrm{H}^{*} \quad \mathrm{~L}-\mathrm{L} \%
$$

14a. Paul reported to the supervisor WHO's lazy.
$\mathrm{H}^{*} \quad \mathrm{H}^{*} \mathrm{~L}-$
$\mathrm{L}^{*} \quad \mathrm{~L}-$
$\mathrm{H}^{*} \mathrm{~L}-\mathrm{L} \%$

14b. Paul reported to the supervisor who's LAZY.
$\mathrm{L}^{*} \quad \mathrm{~L}^{*} \mathrm{~L}-$
$\mathrm{L}^{*} \quad \mathrm{~L}-\mathrm{H}^{*}$
L-L\%

14c. Paul reported to the supervisor whO is always lazy.
L* L* L-
$\mathrm{L}^{*} \quad \mathrm{~L}-\mathrm{L}^{*}$
$\mathrm{H}^{*} \mathrm{~L}-\mathrm{L} \%$

14d. Paul reported to the supervisor who is always LAZY.
$\mathrm{H}^{*} \quad \mathrm{H}-\mathrm{H}^{*} \quad \mathrm{~L}-$
L* L-
$\mathrm{H}^{*} \quad \mathrm{~L}^{*} \mathrm{~L}-\mathrm{L} \%$

15a. Lawrence signaled to the photographer wHO blinked.
$\mathrm{H}^{*} \quad \mathrm{~L}-\mathrm{H}^{*} \quad \mathrm{~L}-$
L* L-
$\mathrm{H}^{*} \mathrm{~L}-\mathrm{L} \%$

15b. Lawrence signaled to the photographer who BLINKED.
$\mathrm{L}^{*} \quad \mathrm{~L}-\mathrm{L}^{*} \mathrm{~L}-$
$\mathrm{L}^{*} \quad \mathrm{~L}-\mathrm{H}^{*}$
$\mathrm{L}-\mathrm{L} \%$

15c. Lawrence signaled to the photographer wHO had just blinked.
$\mathrm{L}^{*} \quad \mathrm{~L}-\mathrm{L}^{*} \mathrm{~L}-$
$\mathrm{L}^{*} \mathrm{~L}-$
$\mathrm{H}^{*} \quad \mathrm{~L}-\mathrm{L} \%$

15d. Lawrence signaled to the photographer who had just BLINKED.

$$
\mathrm{H}^{*} \mathrm{H}-\quad \mathrm{L}^{*} \mathrm{~L}-\quad \mathrm{L}^{*} \mathrm{~L}-\mathrm{H}^{*}
$$

16a. The reporter shouted to the policeman wHO's armed. 


\section{$\mathrm{H}^{*} \mathrm{~L}-\quad \mathrm{L}^{*} \mathrm{~L}-\quad \mathrm{L}^{*} \quad \mathrm{~L}-\quad \mathrm{H}^{*} \quad \mathrm{~L}-\mathrm{L} \%$}

16b. The reporter shouted to the policeman who's ARMED.

$$
\mathrm{L}^{*} \mathrm{~L}-\quad \mathrm{L}^{*} \mathrm{~L}-\quad \mathrm{L}^{*} \mathrm{~L}-\mathrm{H}^{*}
$$

16c. The reporter shouted to the policeman WHO is heavily armed.

$$
\mathrm{L}^{*} \mathrm{~L}-\mathrm{H}^{*} \quad \mathrm{~L}-\quad \mathrm{L}^{*} \quad \mathrm{~L}-\quad \mathrm{H}^{*} \quad \mathrm{~L}-\mathrm{L} \%
$$

16d. The reporter shouted to the policeman who is heavily ARMED.

\section{APPENDIX C}

Sentences used in Experiment 3. The final adjective was the most prominently accented word in all cases. Versions a and c have an IPh before the $w h$-word while versions $\mathrm{b}$ and $\mathrm{d}$ have an iph.

$\mathrm{H}^{*} \mathrm{~L}-\quad \mathrm{H}^{*} \quad \mathrm{~L}^{*} \mathrm{H}-\mathrm{L} \%, \mathrm{H}^{*} \mathrm{~L}-\mathrm{L} \%$

1a. I asked the pretty little girl who's cold.
$\mathrm{H}^{*} \mathrm{~L}-$
$H^{*} \quad L^{*} \quad L^{*} L-$
$\mathrm{H}^{*} \mathrm{~L}-\mathrm{L} \%$

1b. I asked the pretty little girl who's cold.
$\mathrm{H}^{*} \mathrm{~L}-$
$\mathrm{H}^{*}$
L*H-L\% L*
$\mathrm{H}^{*} \mathrm{~L}-\mathrm{L} \%$

1c. I asked the pretty little girl who is very cold.
$\mathrm{H}^{*} \mathrm{~L}-$
$\mathrm{H}^{*}$
$\mathrm{L}^{*} \mathrm{~L}-$
$\mathrm{L}^{*} \quad \mathrm{H}^{*} \mathrm{~L}-\mathrm{L} \%$

1d. I asked the pretty little girl who is very cold.
$\mathrm{H}^{*} \mathrm{H}-\mathrm{H}^{*} \mathrm{~L}-$
$\mathrm{L}^{*}$
$\mathrm{L}^{*} \mathrm{H}-\mathrm{L} \%$
$\mathrm{H}^{*} \mathrm{~L}-\mathrm{L} \%$

2a. Mary told the gentle-looking visitor who's old.
$\mathrm{H}^{*}$
L*L-
$\mathrm{L}^{*}$
$\mathrm{L}^{*} \mathrm{~L}-$ $\mathrm{H}^{*} \mathrm{~L}-\mathrm{L} \%$

2b. Mary told the gentle-looking visitor who's old.
$\mathrm{L}^{*} \quad \mathrm{~L}^{*} \mathrm{~L}-\quad \mathrm{L} *$
L* H-L\%
$\mathrm{L}^{*}$
$\mathrm{H}^{*} \mathrm{~L}-\mathrm{L} \%$

2c. Mary told the gentle-looking visitor who is already quite old.
$\mathrm{L}^{*} \quad \mathrm{~L}^{*} \mathrm{~L}-\quad \mathrm{H}^{*}$
$L^{*} \quad \mathrm{~L}-$
$\mathrm{L}^{*}$
$\mathrm{H}^{*} \mathrm{~L}-\mathrm{L} \%$

2d. Mary told the gentle-looking visitor who is already quite old.
L* L- L* L-
H*H-L\% L* $\mathrm{H}^{*} \quad$ L-L\%

3a. Barbara informed the official who's drunk.
$\mathrm{L}^{*}$
L* L-
$\mathrm{H}^{*} \mathrm{~L}-$
$\mathrm{H}^{*} \quad \mathrm{~L}-\mathrm{L} \%$

3b. Barbara informed the official who's drunk.
$\mathrm{L}^{*}$
$\mathrm{L}^{*} \mathrm{~L}$ -
$\mathrm{H} * \mathrm{H}-\mathrm{L} \%$
$\mathrm{L}^{*}$
$\mathrm{H}^{*} \quad \mathrm{~L}-\mathrm{L} \%$

3c. Barbara informed the official who is publicly drunk.
$\mathrm{L}^{*} \quad \mathrm{~L}-\mathrm{L}^{*} \mathrm{~L}-$
$\mathrm{H}^{*} \mathrm{~L}-$
$\mathrm{L}^{*}$
$\mathrm{H}^{*} \quad \mathrm{~L}-\mathrm{L} \%$

3d. Barbara informed the official who is publicly drunk.

\section{L* L- L* L- L* H-L\% L* H*L-L\%}

4a. Edgar showed the teacher who's new.
$\mathrm{L}^{*} \mathrm{~L}-$
$\mathrm{L}^{*} \mathrm{~L}-$
$\mathrm{L}^{*} \mathrm{~L}-$
$\mathrm{H} * \mathrm{~L}-\mathrm{L} \%$

4b. Edgar showed the teacher who's new.
$\mathrm{L}^{*}$
$\mathrm{L}^{*} \mathrm{~L}$ -
$\mathrm{L}^{*} \mathrm{H}-\mathrm{L} \%$
$\mathrm{L}^{*} \quad \mathrm{H}^{*} \mathrm{~L}-\mathrm{L} \%$

4c. Edgar showed the teacher who is completely new.
$\mathrm{L}^{*} \mathrm{~L}-$
$L^{*} \mathrm{~L}-$
$\mathrm{L}^{*} \quad \mathrm{~L}-\mathrm{L}^{*}$
$\mathrm{L}^{*} \quad \mathrm{H}^{*} \mathrm{~L}-\mathrm{L} \%$

4d. Edgar showed the teacher who is completely new.

$$
L^{*} \quad L^{*} \quad L-L^{*} \quad L^{*} H-L \%, \quad H^{*} \quad \text { L-L\% }
$$

5a. The mysterious spectator taught the player who's good. 


$$
\mathrm{L}^{*} \quad \mathrm{~L}^{*} \quad \mathrm{~L}-\mathrm{L}^{*} \quad \mathrm{~L}^{*} \mathrm{~L}-\quad \mathrm{H}^{*} \mathrm{~L}-\mathrm{L} \%
$$

5b. The mysterious spectator taught the player who's good.

$$
L^{*} \quad L^{*} \quad L-L^{*} \quad L^{*} H-L \% \quad L^{*} \quad H^{*} \quad L-L \%
$$

5c. The mysterious spectator taught the player who is exceptionally good.
$\mathrm{L}^{*}$
$\mathrm{L}^{*} \quad \mathrm{~L}-\mathrm{L}^{*}$
$\mathrm{L}^{*} \mathrm{~L}-\mathrm{L}^{*}$
$\mathrm{L}^{*}$
$\mathrm{H}^{*} \quad \mathrm{~L}-\mathrm{L} \%$

5d. The mysterious spectator taught the player who is exceptionally good.
$\mathrm{H}^{*} \quad \mathrm{~L}^{*} \mathrm{~L}-$
$\mathrm{L}^{*} \mathrm{H}-\mathrm{L} \%$
$\mathrm{H}^{*} \mathrm{~L}-\mathrm{L} \%$

6a. Dick informed the neighbor who's mad.
$\mathrm{H}^{*} \mathrm{~L}-\quad \mathrm{L}^{*} \mathrm{~L}-$
$\mathrm{L}^{*} \quad \mathrm{~L}-$
$\mathrm{H}^{*} \mathrm{~L}-\mathrm{L} \%$

6b. Dick informed the neighbor who's mad.
L* L* L-
$\mathrm{L}^{*} \mathrm{H}-\mathrm{L} \% \mathrm{~L}^{*}$
$\mathrm{L}^{*}$
$\mathrm{H}^{*} \mathrm{~L}-\mathrm{L} \%$

6c. Dick informed the neighbor who is clearly mad.
$\mathrm{H}^{*} \quad \mathrm{~L}^{*} \mathrm{~L}-$
$\mathrm{L}^{*} \quad \mathrm{~L}-$
$\mathrm{L}^{*} \quad \mathrm{H}^{*} \mathrm{~L}-\mathrm{L} \%$

6d. Dick informed the neighbor who is clearly mad.
$\mathrm{L}^{*} \mathrm{~L}-\mathrm{L}$ - L-
$\mathrm{L}^{*} \mathrm{H}-\mathrm{L} \%$
$\mathrm{H}^{*} \quad \mathrm{~L}-\mathrm{L} \%$

7a. Sam reported to the editor who's pregnant.
$\mathrm{L}^{*} \mathrm{~L}-\mathrm{L}^{*}$
L-
$\mathrm{L}^{*} \quad \mathrm{~L}-$
$\mathrm{H}^{*}$
$\mathrm{L}-\mathrm{L} \%$

7b. Sam reported to the editor who's pregnant.
$\mathrm{L}^{*} \mathrm{~L}-\mathrm{L}^{*}$
L-
$\mathrm{L}^{*} \mathrm{H}-\mathrm{L} \% \mathrm{~L}^{*}$
$\mathrm{L}^{*} \quad \mathrm{H}^{*}$
$\mathrm{L}-\mathrm{L} \%$

7c. Sam reported to the editor who is extremely pregnant.
$L * L-L^{*}$
$\mathrm{L}^{*} \quad \mathrm{~L}-\mathrm{L}^{*}$
$\mathrm{L}^{*}$
$\mathrm{H}^{*} \quad \mathrm{~L}-\mathrm{L} \%$

7d. Sam reported to the editor who is extremely pregnant.
$\mathrm{L}^{*} \quad \mathrm{~L}-\quad \mathrm{L}^{*} \quad \mathrm{~L}-$
$\mathrm{L}^{*} \mathrm{H}-\mathrm{L} \% \mathrm{~L}^{*}$
$\mathrm{H}^{*} \mathrm{~L}-\mathrm{L} \%$

8a. The counselor whispered to the student who's mean.

$$
L^{*} \quad \text { L- } \quad L^{*} \quad \text { L- } \quad L^{*} \quad \text { L- } \quad H^{*} \text { L-L\% }
$$

8b. The counselor whispered to the student who's mean.

$$
L^{*} \quad L_{-} \quad L^{*} \quad L-\quad L^{*} \mathrm{H}-\mathrm{L} \% \quad \mathrm{~L}^{*} \quad \mathrm{H}^{*} \mathrm{~L}-\mathrm{L} \%
$$

8c. The counselor whispered to the student who is always mean.

$$
\mathrm{L}^{*} \quad \mathrm{~L}-\mathrm{L}^{*} \quad \mathrm{~L}-\mathrm{L}^{*} \quad \mathrm{~L}-\quad \mathrm{H}^{*} \mathrm{~L}-\mathrm{L} \%
$$

8d. The counselor whispered to the student who is always mean.
$\mathrm{H}^{*} \quad \mathrm{~L}-\mathrm{L}^{*} \quad \mathrm{~L}-$
$\mathrm{L}^{*} \mathrm{H}-\mathrm{L} \%$
$\mathrm{H}^{*} \quad \mathrm{~L}-\mathrm{L} \%$

9a. Elizabeth shouted to the fireman who fainted.

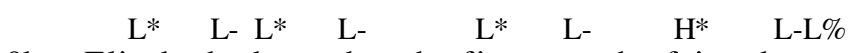

9b. Elizabeth shouted to the fireman who fainted.
$\mathrm{L}^{*} \quad \mathrm{~L}-\mathrm{L}^{*} \quad \mathrm{~L}-$
$\mathrm{L}^{*} \mathrm{H}-\mathrm{L} \%$
$\mathrm{L}^{*} \mathrm{H}^{*}$
L-L\%

9c. Elizabeth shouted to the fireman who had just fainted.

$L^{*} \quad L_{-} L^{*} \quad$ L-
9d. Elizabeth shouted to the fireman who had just fainted.

$$
L^{*} \text { L- L* L- L* H-L\% } \quad \mathrm{H}^{*} \quad \text { L-L\% }
$$

10a. Paula asked the waiter who arrived.

$$
L^{*} \text { L- L* L- } \quad \mathrm{L}^{*} \quad \text { L- } \mathrm{L}^{*} \quad \mathrm{H}^{*} \quad \mathrm{~L}-\mathrm{L} \%
$$

10b. Paula asked the waiter who arrived.

$$
L^{*} \text { L- L* L- L* H-L\% L L } \quad \mathrm{H}^{*} \quad \text { L-L\% }
$$

10c. Paula asked the waiter who had just arrived. 
L*L- L*H-L\% L L* L- L* $\quad \mathrm{H}^{*} \quad$ L-L\%

10d. Paula asked the waiter who had just arrived.

$$
H^{*} \text { L- L*L- L* L*H-L\% L* } \quad \mathrm{H}^{*} \mathrm{~L}-\mathrm{L} \%
$$

11a. The children told the babysitter who's nice.

11b. The children told the babysitter who's nice.

$$
\mathrm{H}^{*} \mathrm{~L}-\mathrm{L}^{*} \mathrm{~L}-\quad \mathrm{L}^{*} \mathrm{~L}^{*} \quad \mathrm{~L}-\quad \mathrm{H}^{*} \mathrm{~L}-\mathrm{L} \%
$$

$$
L^{*} \quad \text { L- L*L- L* L*H-L\% L* } L^{*} \quad \mathrm{H}^{*} \mathrm{~L}-\mathrm{L} \%
$$

11c. The children told the babysitter who is always so nice.

$$
L^{*} \text { L- L*L- L* L* L- } \quad \mathrm{L}^{*} \quad \mathrm{H}^{*} \mathrm{~L}-\mathrm{L} \%
$$

11d. The children told the babysitter who is always so nice.

$$
H^{*} L_{-} \quad L^{*} \quad \text { L- } \quad L^{*} H-L \% L^{*}, \quad H^{*} \text { L-L\% }
$$

12a. The producer informed the actress who's late.

$$
L^{*} \mathrm{~L}-\quad \mathrm{L}^{*} \quad \mathrm{~L}-\quad \mathrm{L}^{*} \quad \mathrm{~L}-\quad \mathrm{H}^{*} \mathrm{~L}-\mathrm{L} \%
$$

12b. The producer informed the actress who's late.
$\mathrm{L}^{*} \mathrm{~L}-\quad \mathrm{L} * \mathrm{~L}-$
L* H-L\%
$\mathrm{L}^{*}$
$H^{*} \mathrm{~L}-\mathrm{L} \%$

12c. The producer informed the actress who is typically late.

$$
\mathrm{L}^{*} \mathrm{~L}-\quad \mathrm{L}^{*} \mathrm{~L}-\mathrm{L} \mathrm{L}^{*} \mathrm{~L}-\quad \mathrm{L}^{*} \quad \mathrm{H}^{*} \mathrm{~L}-\mathrm{L} \%
$$

12d. The producer informed the actress who is typically late.

$$
\text { L*L- L* }^{*} \text { L- L* H-L\% , H* L-L\% }
$$

13a. Sally taught the tourist who's weird.

$$
\text { L*L- L* L- } \quad \text { L*}^{*} \quad \text { L- } \text { L*}^{*}, \quad \mathrm{H}^{*} \quad \text { L-L\% }
$$

13b. Sally taught the tourist who's weird.
L*L- L* L-
$\mathrm{L}^{*} \mathrm{H}-\mathrm{L} \%$
$\mathrm{L}^{*} \quad \mathrm{H}^{*} \quad \mathrm{~L}-\mathrm{L} \%$

13c. Sally taught the tourist who is really weird.
L*L- L* L- L* L-
$\mathrm{H}^{*} \quad \mathrm{~L}-\mathrm{L} \%$

13d. Sally taught the tourist who is really weird.

$$
L^{*} \quad L^{*} \text { L- } \quad L^{*} \quad L^{*} H-L \% \quad H^{*} \text { L-L\% }
$$

14a. Paul reported to the supervisor who's lazy.
$\mathrm{L} * \mathrm{~L}-\quad \mathrm{L} * \mathrm{~L}-$
$\mathrm{L}^{*} \quad \mathrm{~L}^{*} \mathrm{~L}-$
$\mathrm{H}^{*} \mathrm{~L}-\mathrm{L} \%$

14b. Paul reported to the supervisor who's lazy.
$\mathrm{L}^{*} \mathrm{~L}-\mathrm{L}^{*} \mathrm{~L}-$
$\mathrm{L}^{*} \quad \mathrm{~L}^{*} \mathrm{H}-\mathrm{L} \%$
$\mathrm{L}^{*}$
$\mathrm{H}^{*} \mathrm{~L}-\mathrm{L} \%$

14c. Paul reported to the supervisor who is always lazy.

$$
L^{*} \quad L^{*} \text { L- } \quad L^{*} \quad L^{*} \text { L- } L^{*} \quad H^{*} \mathrm{~L}-\mathrm{L} \%
$$

14d. Paul reported to the supervisor who is always lazy.

$$
\mathrm{L}^{*} \quad \mathrm{~L}_{-} \quad \mathrm{L}^{*} \quad \mathrm{~L}-\quad \mathrm{L}^{*} \quad \mathrm{H}-\mathrm{L} \% \quad \mathrm{H}^{*} \quad \mathrm{~L}-\mathrm{L} \%
$$

15a. Lawrence signaled to the photographer who blinked.
L* L- L* L-
$\mathrm{L}^{*}$
L- $\quad \mathrm{H}^{*} \quad$ L-L\%

15b. Lawrence signaled to the photographer who blinked.
$\mathrm{L}^{*} \quad \mathrm{~L}-\mathrm{L}^{*} \mathrm{~L}-$
$L^{*} \quad \mathrm{H}-\mathrm{L} \%$
$\mathrm{L}^{*} \quad \mathrm{H}^{*} \quad \mathrm{~L}-\mathrm{L} \%$

15c. Lawrence signaled to the photographer who had just blinked.
$\mathrm{L}^{*} \quad \mathrm{~L}-\mathrm{L}^{*} \mathrm{~L}-$
$L^{*} \quad L-L^{*}$
$\mathrm{H}^{*} \quad \mathrm{~L}-\mathrm{L} \%$

15d. Lawrence signaled to the photographer who had just blinked.
$\mathrm{H}^{*} \mathrm{~L}-\mathrm{L}^{*} \mathrm{~L}-$
$\mathrm{L}^{*} \mathrm{H}-\mathrm{L} \%$
$\mathrm{H}^{*}$
L-L\%

16a. The reporter shouted to the policeman who's armed. 


$$
\mathrm{L}^{*} \mathrm{~L}-\quad \mathrm{L}^{*} \mathrm{~L}-\quad \mathrm{L} * \quad \mathrm{~L}-\quad \mathrm{H}^{*} \quad \mathrm{~L}-\mathrm{L} \%
$$

16b. The reporter shouted to the policeman who's armed.

$$
\mathrm{H}^{*} \mathrm{~L}-\mathrm{L} * \mathrm{~L}-\quad \mathrm{L} * \mathrm{H}-\mathrm{L} \% \quad \mathrm{~L}^{*} \quad \mathrm{H}^{*} \quad \mathrm{~L}-\mathrm{L} \%
$$

16c. The reporter shouted to the policeman who is heavily armed.

$$
\mathrm{L}^{*} \mathrm{~L}-\mathrm{L}^{*} \mathrm{~L}-\quad \mathrm{L}^{*} \quad \mathrm{~L}-\quad \mathrm{L}^{*} \quad \mathrm{H}^{*} \quad \mathrm{~L}-\mathrm{L} \%
$$

16d. The reporter shouted to the policeman who is heavily armed.

\section{APPENDIX D}

Sentences used in Experiment 5. Most prominently accented words indicated in uppercase. $\mathrm{H}^{*}, \mathrm{~L}^{*}$, $\mathrm{L}+\mathrm{H}^{*}=$ high, low, and low-plus-high pitch accents; ! $\mathrm{H}^{*}=$ downstepped high pitch accent; H-, L=high and low phrase accents; $\mathrm{L} \%=$ low boundary tone
$\mathrm{L}^{*} \mathrm{~L}-$
$L^{*} \quad$ L- $\quad L+H^{*}$
L-L\%

1a. Carla let Bert know wHEN she found out the truth.
$\mathrm{L}^{*} \mathrm{~L}-\quad \mathrm{L}^{*} \quad \mathrm{~L}-$
$\mathrm{L}+\mathrm{H} * \mathrm{~L}-\mathrm{L} \%$

1b. Carla let Bert know when she found out the TRUTH.
$\mathrm{L} * \mathrm{~L}-$
$\mathrm{L}^{*}$
$\mathrm{L}-\quad \mathrm{L}+\mathrm{H}^{*}$
$\mathrm{L}-\mathrm{L} \%$

2a. Bob asked the flight attendant WHEN she was serving the meal.
L*L-
$L^{*}$
L-
$\mathrm{H}^{*}$
$\mathrm{L}+\mathrm{H}^{*} \mathrm{~L}-\mathrm{L} \%$

2b. Bob asked the flight attendant when she was serving the MEAL.
$\mathrm{L}^{*} \quad \mathrm{~L}-\mathrm{L}^{*}$
$\mathrm{L}^{*} \mathrm{H}-\mathrm{L}+\mathrm{H}^{*}$
$\mathrm{L}-\mathrm{L} \%$

3a. Joshua began to wonder WHEN his girlfriend got a tattoo.
$\mathrm{L}^{*} \quad \mathrm{~L}-\mathrm{L}^{*} \quad \mathrm{~L}^{*} \mathrm{~L}-$
$L^{*}$
$\mathrm{L}+\mathrm{H} * \mathrm{~L}-\mathrm{L} \%$

3b. Joshua began to wonder when his girlfriend got a TAтTOO.
$\mathrm{L}^{*} \mathrm{~L}-$
$\mathrm{L}^{*} \mathrm{~L}-\mathrm{L}+\mathrm{H}^{*}$

$\mathrm{L}-\mathrm{L} \%$

4a. The woman told the F.B.I. wHEN she got another strange letter.
$\mathrm{L}^{*} \mathrm{~L}-$
$\mathrm{L}^{*} \mathrm{H}-$
$\mathrm{L}+\mathrm{H}^{*}$
L-L\%

4b. The woman told the F.B.I. when she got ANOTHER strange letter.

$$
\mathrm{L}^{*} \mathrm{~L}-\mathrm{L} * \mathrm{~L}-\quad \mathrm{L} * \mathrm{~L}-\quad \mathrm{L}+\mathrm{H}^{*}
$$

5a. The dentist asked his assistant WHEN she was scheduling appointments.
$\mathrm{L}^{*} \mathrm{~L}-\mathrm{L} * \mathrm{~L}-$
$\mathrm{L}^{*} \mathrm{~L}-$
$\mathrm{L}^{*} \quad \mathrm{~L}+\mathrm{H}^{*}$
$\mathrm{L}-\mathrm{L} \%$

5b. The dentist asked his assistant when she was scheduling APPOINTMENTs.
$\mathrm{H}^{*} ! \mathrm{H}^{*}$
! $\mathrm{H}^{*} \mathrm{H}-\mathrm{L}+\mathrm{H}^{*}$
$\mathrm{L}-\mathrm{L} \%$

6a. The ship steward shouted wHEN the boat was pulling out of dock.

$$
\mathrm{H}^{*} ! \mathrm{H}^{*} \quad ! \mathrm{H}^{*} \mathrm{H}-\quad \mathrm{L}+\mathrm{H}^{*} \mathrm{~L}-\mathrm{L} \%
$$

6b. The ship steward shouted when the boat was pulling out of DOCK.
$\mathrm{L}^{*} \quad \mathrm{H}-$
$\mathrm{L}^{*}$
$\mathrm{L} * \mathrm{~L}-\mathrm{L}+\mathrm{H}^{*}$
$\mathrm{L}-\mathrm{L} \%$

7a. Jaquelyn reminded her son wHEN he was doing the laundry.
$\mathrm{L}^{*} \quad \mathrm{H}-$
$\mathrm{L}^{*}$
L- L*
$\mathrm{L}+\mathrm{H}^{*} \quad \mathrm{~L}-\mathrm{L} \%$

7b. Jaquelyn reminded her son when he was doing the LAUNDRY.
$\mathrm{L}^{*} \mathrm{H}-$
$\mathrm{L}^{*} \quad \mathrm{~L}-\mathrm{L}+\mathrm{H}^{*}$
L-L\%

8a. Violet let her kids know wHEN they were going to grandma's.
$\mathrm{L}^{*} \mathrm{H}-$
L* L-
$\mathrm{L}+\mathrm{H}^{*}$ $\mathrm{L}-\mathrm{L} \%$

8b. Violet let her kids know when they were going to GRANDMA's. 

$\mathrm{L}^{*} \mathrm{~L}-$
$\mathrm{L}^{*} \quad \mathrm{~L}-\mathrm{L}+\mathrm{H}^{*}$
L- $\mathrm{L}^{*}$
$\mathrm{L}-\mathrm{L} \%$

9a. Paul started wondering WHEN his boss shredded all the old files.
$\mathrm{L}^{*} \mathrm{~L}-$
$\mathrm{L}^{*} \quad \mathrm{~L}-$

$\mathrm{L}^{*} \mathrm{~L}-\quad \mathrm{L}^{*}$

$\mathrm{L}+\mathrm{H}^{*} \mathrm{~L}-\mathrm{L} \%$

9b. Paul started wondering when his boss shredded all the old FILES.
$L^{*} \quad$ L- $L^{*}$
L- $\mathrm{L}+\mathrm{H}^{*}$
L-L\%

10a. Evelyn reconsidered WHEN she found tracks in the snow.
$L^{*} \quad$ L- $L^{*}$
L-
$L^{*}$
$\mathrm{L}+\mathrm{H}^{*} \mathrm{~L}-\mathrm{L} \%$

10b. Evelyn reconsidered when she found tracks in the sNow.
$\mathrm{L}^{*} \mathrm{~L}-$
$\mathrm{L}^{*} \mathrm{~L}-\mathrm{L}+\mathrm{H}^{*}$
$L^{*} \quad \mathrm{~L}-$
$\mathrm{L}^{*}$
$\mathrm{L}^{*} \quad \mathrm{~L}-\mathrm{L} \%$

11a. Billy confessed WHEN his partner started smuggling heroin.
$\mathrm{L}^{*} \mathrm{~L}-\quad \mathrm{L}^{*} \mathrm{~L}-$
$\mathrm{L}^{*} \mathrm{~L}-$
$\mathrm{L}^{*} \quad \mathrm{~L}+\mathrm{H}^{*} \quad \mathrm{~L}-\mathrm{L} \%$

11b. Billy confessed when his partner started smuggling HEROIN.
$\mathrm{L}^{*}$
$\mathrm{H}-\mathrm{L}+\mathrm{H}^{*}$
L-L\%

12a. The professor noticed WHEN the students finished the exam.<smiles>[124IH]</smiles>

$\mathrm{L}+\mathrm{H} * \mathrm{~L}-\mathrm{L} \%$

12b. The professor noticed when the students finished the EXAM. 